Cómo citar este trabajo: Morote Seguido, A. F., \& Rico Amorós, A. M. (2018). Perspectivas de funcionamiento del trasvase Tajo-Segura (España): efectos de las nuevas reglas de explotación e impulso de la desalinización como recurso sustitutivo. Boletín de la Asociación de Geógrafos Españoles, 79, 2754, 1-43. http://dx.doi.org/10.21138/bage.2754

\title{
Perspectivas de funcionamiento del Trasvase Tajo-Segura (España): efectos de las nuevas reglas de explotación e impulso de la desalinización
} como recurso sustitutivo

Perspectives of operation of the Tajo-Segura Transfer (Spain): new rules of operation and the impulse of the desalination as replacement resource

\author{
Álvaro Francisco Morote Seguido \\ alvaro.morote@ua.es \\ Departamento de Didáctica de las Ciencias Experimentales y Sociales \\ Universidad de Valencia (España)
}

\begin{abstract}
Antonio Manuel Rico Amorós
am.rico@ua.es

Instituto Interuniversitario de Geografía

Universidad de Alicante (España)
\end{abstract}

\section{Resumen}

El Trasvase Tajo-Segura se ha convertido desde su inauguración en 1979 en una de las infraestructuras hidráulicas que más tensiones interterritoriales ha originado en España. A ello se une su valor estratégico para el desarrollo de las provincias del sureste peninsular, donde atiende consumos agrícolas y urbano-turísticos con grandes implicaciones sociales y económicas. El 
objetivo de este trabajo es analizar las causas y las consecuencias del funcionamiento del Trasvase Tajo-Segura con la reciente modificación de sus normas de explotación (límite de no trasvase cuando en los embalses de cabecera almacenen menos de $400 \mathrm{hm}^{3}$ ) y el impulso de la desalinización en la cuenca receptora como sustitución a los trasvases. Para ello se han analizado los efectos del funcionamiento de las nuevas normas de explotación y se plantean posibles alternativas para resolver un conflicto que se agrava durante cada ciclo de intensa y prolongada sequía sin que el Estado ni las autonomías, a través de la planificación hidrológica, hayan dado una respuesta satisfactoria a las regiones cedentes y receptoras.

Palabras clave: agua; planificación; conflictos; trasvase Tajo-Segura; desalinización; España.

\begin{abstract}
The Tagus-Segura Transfer has become since its inauguration in 1979 in one of the hydraulic infrastructures with more interterritorial tensions in Spain. This is due to his strategic value for the development of the peninsular southeast where it attends agricultural and urban-tourist water consumption with great social and economic implications. The objective of this research is analyze the causes and the possible consequences of the operation of the Tagus-Segura Transfer with the recent modification of his exploitation rules (increase of the level of no transfer in $400 \mathrm{hm}^{3}$ in the headwater) and the increase of the desalination in the receiving regions as a replacement of transfers. To this end, the effects of the operation of the new exploitation rules and the possible alternatives have been analyzed to resolve a conflict that gets worse during each cycle of intense and prolonged drought, without the State and the autonomies through hydrological planning, has given a satisfactory response to the donor and recipient regions.
\end{abstract}

Key words: water; planning; conflict; Tagus-Segura transfer; desalination; Spain.

\title{
1 Introducción
}

El agua ha sido considerada tradicionalmente como el recurso natural que ha posibilitado la existencia de vida y desarrollo (Cabello et al., 2017). Ante el fuerte crecimiento socio-económico global que han vivido los países desarrollados durante la segunda mitad del siglo pasado, han sido numerosas las actuaciones hidráulicas dirigidas a incrementar la oferta de agua para garantizar la fuerte expansión de usos urbanos, agrícolas y de producción hidroeléctrica (Tortajada, 2016). En el caso español, la disponibilidad de agua en cantidad y calidad suficientes ha adquirido un interés de primer orden para atender las demandas urbanas, turísticas y agrícolas, especialmente en territorios semiáridos (Flores, 2004; Fanlo, 2008; Rico et al., 2013). La planificación hidráulica de los países desarrollados se fundamentó en un primer momento en la llamada "vieja política hidráulica" basada en la construcción de canales, trasvases y embalses y, desde las últimas décadas del pasado siglo 
$X X$, con el impulso de las llamadas "fuentes no convencionales" o "alternativas" como son el uso de aguas regeneradas depuradas y la desalinización (Fragkou \& McEvoy, 2016; Morote et al., 2017a).

Los conflictos que originan los trasvases se relacionan directamente con una sensación de "falta de equidad" en las decisiones de asignación de recursos hídricos y, cada vez más, con la defensa de los valores ambientales y patrimoniales de las cuencas cedentes (Morote et al., 2017c). Por ejemplo, en los EE.UU. en la década de los setenta, los grandes proyectos hidráulicos llevaron consigo críticas por razones económicas (altos costes y dificultades de financiación), sociales (resistencia frente a la construcción de presas y transferencias de agua, por parte de la población local), y ambientales (impactos sobre los ecosistemas). Durante las siguientes décadas, las protestas se extenderían al mundo en desarrollo llegando al punto que la lucha contra los grandes embalses y trasvases, constituyen hoy en día uno de los "puntos calientes" de los conflictos socio-ambientales en América Latina, Asia y África (McCully, 1996; World Commission on Dams, 2000; Metha, 2011)

En el caso español funcionan más de 40 trasvases de agua con una capacidad de suministro de unos $1300 \mathrm{hm}^{3} /$ año, lo que representa menos del $3 \%$ de los recursos garantizados que se cifran en $46000 \mathrm{hm}^{3}$. Adquieren gran significación territorial los trasvases Tajo-Segura (650 hm²/año) (conocido también como Acueducto Tajo-Segura, ATS), Ter-Llobregat (229 hm³/año), EbroTarragona (121,6 hm³/año), Zadorra-Arratia (150 hm³/año), Guadiaro-Majaceite (110 hm³/año), Júcar-Turia $\left(110 \mathrm{hm}^{3}\right.$ ), Júcar-Vinalopó $\left(70 \mathrm{hm}^{3} /\right.$ año), Negratín-Almanzora (50 hm³/año) y EbroBesaya $\left(26 \mathrm{hm}^{3} /\right.$ año). Los trasvases inter-cuencas se han considerado como la manifestación por excelencia de la planificación hidráulica en el ámbito nacional, al significar la culminación de la intervención pública para reequilibrar las disponibilidades hídricas y garantizar suministros agrícolas, urbanos y turísticos con grandes implicaciones sociales y económicas (Gil \& Gómez, 2017; Gómez-Espín, 2017; Morales et al., 2005). Sin embargo han sido objeto de creciente polémica y de posturas antagónicas ya que las cuencas receptoras intentan que éstos se realicen lo antes posible, aduciendo criterios de solidaridad y de equilibrio; mientras que las cedentes se oponen a las transferencias, alegando que no existen excedentes y que el recurso debe utilizarse en los lugares de origen para favorecer su desarrollo económico (Melgarejo, 2000; Sala, 2009).

Apoyándose en la Directiva Marco de Agua 2000/60/CE, diferentes autores ponen en cuestión este tipo de infraestructuras en el territorio europeo, debido a su elevado impacto económico y ambiental y la necesidad de plantear alternativas de planificación hidrológica que consideren en mayor grado la preservación de las masas de agua (Baeza, 2013; Del Moral y Silva, 2006; Ferreira, 2013; Gallego, 2013). Como afirman Hernández-Mora et al. (2010), la construcción de grandes y costosas infraestructuras hidráulicas ha condicionado fuertemente la gestión del agua, 
estableciendo relaciones institucionales y políticas para justificar su construcción en respuesta a las fuertes presiones realizadas por diferentes grupos sociales para beneficio propio. Estos factores reducen en gran medida la posibilidad de introducir criterios de eficiencia o racionalidad económica o ambiental en decisiones de gestión, incluso si finalmente sólo se satisfacen las necesidades de una minoría. Además, las transferencias inter-cuencas agravan las tensiones entre diferentes regiones por cuestiones socio-económicas y ambientales por la tenencia del recurso (Saurí \& Del Moral, 2001). En este escenario han cobrado gran protagonismo las comunidades autónomas, olvidando con mucha frecuencia que la fundamentación jurídica de las transferencias hídricas radica en la titularidad estatal sobre el dominio público hidráulico. Por tanto, el debate sobre los trasvases constituye un tema controvertido y complejo de abordar, dadas sus implicaciones en la ordenación territorial y las repercusiones sociales, ambientales y económicas en las áreas afectadas. Como indican Morales et al. (2005), el mantenimiento de estas infraestructuras dependerá de su aceptación por la sociedad española siempre que redunden en un beneficio para todas la comunidades autónomas, por encima de los intereses localistas de unos y otros.

En el sureste peninsular español, área beneficiada por el ATS, con el fin de garantizar las demandas de agua tanto para el sector agrícola (antiguas y nuevas áreas de regadío) como el suministro para usos urbano-turísticos, incrementadas desde los años sesenta y setenta del pasado siglo, se ha recurrido a soluciones hidráulicas tradicionales, como trasvases y explotación de acuíferos, unidas al creciente empleo de fuentes no convencionales y al incremento de la eficiencia del uso del agua en regadíos y abastecimientos (Gómez et al., 2011; Rico et al., 2014; 2016). Todo ello, cabe relacionarlo con las características intrínsecas de la cuenca receptora del mencionado trasvase (cuenca del Segura), caracterizada por una profunda aridez motivada por factores de orden climático, hidrográfico e hidrogeológico (Gil, 2016). En este sentido, ya desde época romana, la penuria natural de agua que padece este territorio propició que el agua adquiriese el carácter de bien por excelencia, originando una cultura histórica con sistemas originales y reglamentaciones muy minuciosas para su captación, distribución y aprovechamiento (Morales et al., 2005). Por ello, con referencia a la cuenca del Segura, el desfase existente entre oferta (1636 hm $\mathrm{hm}^{3}$ año) y demanda (1726 hm³/año) de agua obedece, sobre todo, a la aridez, a la intensificación del consumo y a las mutaciones cualitativas que han afectado a la mayoría de usos a partir de la segunda mitad del pasado siglo XX (Hernández \& Morales, 2009; Vera et al., 2009; Morote \& Hernández, 2016). Por lo tanto, este desfase existente se debe a unas demandas muy por encima de los recursos hídricos disponibles, incluso teniendo en cuenta los recursos no convencionales y transferencias desde otras cuencas.

Los impactos y los beneficios que genera el ATS sobre el conjunto de la economía de los territorios receptores son complejos de valorar, ya que dependen de factores diversos, como la propia disponibilidad del recurso, los efectos de las sequías, la eficiencia de uso o la desigual repercusión 
socio-económica que tienen los consumos agrícolas en comparación con los urbano-turísticos y los industriales (Hernández \& Morales, 2008). Sin embargo, sí que existe un denominador común a todos los usos del agua del ATS, como es su elevada trascendencia social y económica (GómezEspín, 2017). Estos recursos benefician actualmente a 147276 ha de regadíos hortofrutícolas de vocación exportadora y a más de 2,5 millones de habitantes de las provincias de Almería, Alicante y Murcia, con un área de influencia cercana a los $20000 \mathrm{~km}^{2}$, de las cuencas del Segura, Júcar y Sur (Almanzora) (SCRATS, 2016). En estas cuatro décadas de funcionamiento del ATS se ha evidenciado lo necesario que fue su construcción para asegurar el desarrollo socio-económico (desde su construcción en 1979) del sureste peninsular, pues sus aguas han sido las impulsoras de la actividad turística del litoral, la agricultura y de algunas industrias (Morales et al., 2005). Igualmente, los regadíos creados durante el último cuarto del siglo XX en el Campo de Cartagena, Bajo Segura y Valle del Guadalentín, constituyen en la actualidad una de las zonas de regadío con mayor repercusión socio-económica de España (147 276 hectáreas de superficie bruta), es decir, con dotación y con derecho a riego con aguas procedentes del Tajo (una media de $201 \mathrm{hm} 3 /$ año entre 1979-2017). Cabe indicar que estas áreas de uso utilizan otras fuentes de recursos en un "mix" de oferta. Es decir, la participación de cada entidad de regantes en los recursos del ATS es diferente dependiendo de las zonas de riego, pudiendo representar desde la única fuente de recursos disponible, a participar en menos del $10 \%$ del total de recursos empleados en algunas explotaciones. Así, 54950 ha se riegan exclusivamente con aguas procedentes del ATS (el 37 \%) mientras que el resto, con una extensión de 95000 ha (el 63 \%) utiliza el agua del ATS como apoyo para complementar su dotación de recursos de otra procedencia (aguas superficiales de la cuenca del Segura, aguas subterráneas, aguas depuradas regeneradas y desalinizadas) (Melgarejo et al., 2010).

A la situación de desfase entre oferta y demanda de recursos hídricos, se une la incertidumbre sobre los recursos hídricos futuros en el marco del proceso de calentamiento térmico planetario por efecto invernadero de causa antrópica (IPCC, 2014) que en algunas regiones del mundo, como la península Ibérica, puede ocasionar una disminución de las precipitaciones y una mayor intensidad de los periodos de sequía. En este sentido, en España, se ha realizado modelización regional de precipitaciones y de recursos de agua circulante que, en ambos casos, señalan una disminución más cuantiosa en los territorios situados al sur del paralelo 40 norte (AEMET, 2017; CEDEX, 2011).

\section{Objetivos y metodología}

El objetivo de esta investigación es analizar las causas que han propiciado la modificación de las reglas de explotación del ATS (vigentes desde 1980), y la aprobación de unas nuevas normas más conservadoras en la Ley 21/2013 de 9 de diciembre, de Evaluación Ambiental y la Ley 21/2015, 
de 20 de julio, de Montes. Junto a este objetivo, se plantean también las posibles consecuencias que derivan de estas reglas, se analiza el papel que puede conllevar el impulso de la desalinización a gran escala en la cuenca receptora y se plantean posibles alternativas para resolver un conflicto surgido incluso antes de la finalización del trasvase en 1979, que se ha agravado durante cada ciclo de intensa y prolongada sequía sin que el Estado, ni las comunidades autónomas hayan logrado poner solución a los problemas de escasez de agua que padece la cuenca del Segura.

\section{Tabla 1. Normativa y planes consultados con influencia en el funcionamiento del Trasvase Tajo-Segura}

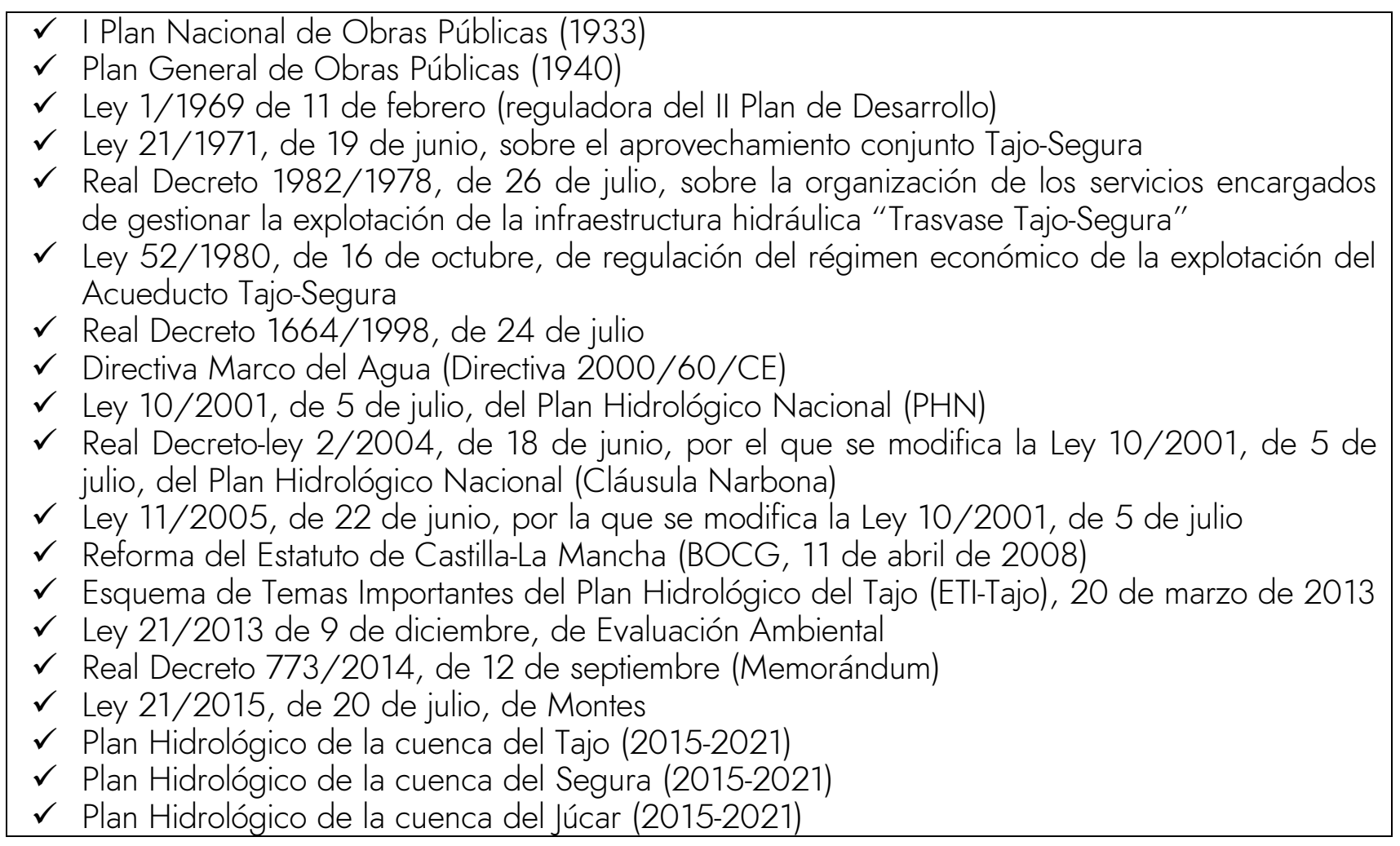

Fuente: elaboración propia

Metodológicamente se han consultado diferentes normativas y planes que han tenido y tienen en la actualidad una influencia sobre el funcionamiento del ATS (Tabla 1). En segundo lugar se han realizado diferentes reuniones con los directores y técnicos de los principales usuarios y entidades públicas y privadas beneficiarios del ATS en el sureste peninsular durante 2016 y 2017, para poder conocer de primera mano las necesidades, efectos y sus realidades en torno al funcionamiento de esta infraestructura: Acuamed, Ministerio de Agricultura, Alimentación y Medio Ambiente, Mancomunidad de los Canales del Taibilla (MCT), Comisión de Precios de la Generalitat Valenciana, Sindicato Central de Regantes del Acueducto Tajo-Segura (SCRATS) y Junta Central de Usuarios del Vinalopó-l'Alacantí. Todas las reuniones se realizaron bajo un mismo guion común y con unos temas estructurados en torno a: 
a) Factores políticos: Derogación del Plan Hidrológico Nacional, aprobación del Programa A.G.U.A. (2004), impacto del cambio en la ley que regula los volúmenes de transferencia del ATS y repercusiones en el futuro

b) Factores socio-económicos: principales impactos so socio-económicos que ha permitido el ATS en la cuenca del Segura

c) El impulso de la desalinización: balance de este recurso no convencional como solución y sustitución a los trasvases

d) Soluciones para contrarrestar el cierre del ATS durante situaciones de sequía

Junto con la anterior información recopilada se han obtenido datos de evolución del histórico de transferencias totales y por usos del ATS (1979-2017) facilitados por el Sindicato Central de Regantes del Acueducto Tajo Segura y datos de evolución de las fuentes de suministro de la Mancomunidad de los Canales del Taibilla (1989-2017) (principal organismo que suministra agua en alta al sureste peninsular). Con estos datos e información se ayudará a interpretar y valorar el peso e importancia que, tanto las aguas procedentes del ATS como de la desalinización, tienen en la cuenca receptora. Finalmente, se han obtenido los datos mensuales de almacenamiento en los embalses de cabecera (2004/05-2017/18) proporcionados por el Boletín Hidrológico (Ministerio de Agricultura, Alimentación y Medio Ambiente).

\section{Resultados}

\subsection{Las nuevas reglas de explotación del Trasvase Tajo-Segura: mayor seguridad jurídica y considerable incremento del umbral de "no trasvase" en Entrepeñas y Buendía}

El Gobierno de España ha introducido una serie de modificaciones en la legislación de aguas a través de la Ley de Evaluación Ambiental (Ley 21/2013 de 9 de diciembre), que han variado sustancialmente el régimen de funcionamiento del ATS. Las nuevas reglas de explotación de esta infraestructura han sido establecidas por la disposición adicional decimoquinta de la Ley 21/2015, de 20 de julio, de Montes y en el Real Decreto 773/2014, de 12 de septiembre, por el que se aprueban diversas normas reguladoras del ATS, que habían sido recogidas en el llamado "Memorándum", un documento acordado entre el Gobierno de España y las Comunidades Autónomas de Murcia y la Comunidad Valenciana, al que se adhirieron en una fase posterior las Comunidades de Castilla-La Mancha, Madrid y Extremadura (Melgarejo et al., 2014).

La Ley 21/2013 de 9 de diciembre, de Evaluación Ambiental, introdujo modificaciones significativas en la regulación del ATS, con preferencia de la cuenca cedente y respetando las determinaciones de su planificación hidrológica. En principio, tenían por objeto mejorar la regulación normativa de esta infraestructura, estableciendo unas reglas técnicas objetivas que eliminasen la inseguridad y precariedad antes existente y proporcionasen criterios objetivos y 
transparentes sobre la forma de operación de esta transferencia. Estas nuevas modificaciones se justifican debido a las directrices que se imponen desde la Comisión Europea, concretamente en la Directiva Marco del Agua (DMA 2000/60/CE) en la que se establecía que para el año 2015 y en adelante, se debería haber logrado el "buen estado ecológico de las masas de aguas".

La "Propuesta de Proyecto del Plan Hidrológico de cuenca de la Parte Española de la Demarcación Hidrográfica del Tajo" (anterior Plan de 2014), cuyo periodo de información y consulta pública se inició el 20 de marzo de 2013, incluyó en su documentación técnica (Memoria y Documento Auxiliar de la Memoria 4. Modelo del Eje del Tajo) y en el borrador de Normativa (Artículo 26 y Disposición Transitoria única) una serie de determinaciones que afectarían significativamente el normal funcionamiento del ATS. La referida Normativa establecía en su Artículo 26 una profunda modificación de las reglas de explotación que regían en el funcionamiento del trasvase, estableciendo que "no se podrán efectuar trasvases, en ningún caso, cuando las existencias en Entrepeñas y Buendía no superen los $400 \mathrm{hm}^{3}$ ". Esta determinación significaba que el umbral mínimo de "no trasvase" se elevaba de 240 a $400 \mathrm{hm}^{3}$ y, además, vino acompañada de una modificación sustancial de las reglas de explotación, particularmente de las condiciones hidrológicas excepcionales previstas en el Real Decreto 2530/1985 para elevar las decisiones del Trasvase de la Comisión Central de Explotación al Consejo de Ministros, y que marcan el límite entre los niveles 2 (volumen trasvasable de $38 \mathrm{hm}^{3} /$ mes) y 3 (volumen trasvasable de $20 \mathrm{hm}^{3} / \mathrm{mes}$ ) (Tabla 2).

\section{Tabla 2. Nuevas reglas de explotación del Trasvase Tajo-Segura. \\ Niveles mensuales de transferencias en función del caudal almacenado en cabecera (Entrepeñas y Buendía)}

Nivel 1. Se dará cuando las existencias conjuntas en Entrepeñas y Buendía sean iguales o
mayores que $1300 \mathrm{hm}^{3}$, o cuando las aportaciones conjuntas entrantes a estos embalses en
los últimos doce meses sean iguales o mayores que $1200 \mathrm{hm}^{3}$. En este caso el órgano
competente autorizará un trasvase mensual de $60 \mathrm{hm}^{3}$, hasta el máximo anual.
Nivel 2 . Se dará cuando las existencias conjuntas de Entrepeñas y Buendía sean inferiores a
$1300 \mathrm{hm}^{3}$, sin llegar a los volúmenes previstos en el Nivel 3, y las aportaciones conjuntas
registradas en los últimos doce meses sean inferiores a $1200 \mathrm{hm}^{3}$. En este caso el órgano
competente autorizará un trasvase mensual de $38 \mathrm{hm}^{3}$, hasta el máximo anual. Nivel 3. Se dará cuando las existencias conjuntas en Entrepeñas y Buendía no superen, a comienzos de cada mes: Octubre $\left(613 \mathrm{hm}^{3}\right)$, Noviembre $\left(609 \mathrm{hm}^{3}\right)$, Diciembre (605), Enero $\left(602 \mathrm{hm}^{3}\right)$, Febrero $\left(597 \mathrm{hm}^{3}\right)$, Marzo $\left(591 \mathrm{hm}^{3}\right)$, Abril $\left(586 \mathrm{hm}^{3}\right)$, Mayo $\left(645 \mathrm{hm}^{3}\right)$, Junio, $\left(673 \mathrm{hm}^{3}\right)$, Julio $\left(688 \mathrm{hm}^{3}\right)$, Agosto $\left(661 \mathrm{hm}^{3}\right)$, Septiembre $\left(631 \mathrm{hm}^{3}\right)$. En este nivel, denominado como de situación hidrológica excepcional, el órgano competente podrá autorizar discrecionalmente y de forma motivada un trasvase de hasta $20 \mathrm{hm}^{3} / \mathrm{mes}$.

Nivel 4. Se dará esta situación cuando las existencias conjuntas en Entrepeñas y Buendía sean inferiores a $400 \mathrm{hm}^{3}$, en cuyo caso no cabe aprobar trasvase alguno.

Fuente: elaboración propia a partir de la ley 21/2015, de 20 de julio, por la que se modifica la Ley 43/2003, de 21 de noviembre, de Montes 
El cambio tan profundo de las reglas de explotación del ATS (art. 26 de la Propuesta de Proyecto del anterior Plan Hidrológico de la cuenca del Tajo), se justificó por la necesidad de atender nuevas demandas de abastecimiento en el sistema de la cabecera del Tajo. Y a ello se unió la restricción que suponía el caudal mínimo circulante que debe garantizarse en el Tajo a su paso por Aranjuez, antes de su confluencia con el Jarama, que se ha mantenido en $6 \mathrm{~m}^{3} / \mathrm{s}$, conforme establecía la Ley 52/1980 y el actual Plan Hidrológico de la cuenca del Tajo (2015-2021). Como se ha comentado, entre las medidas introducidas cabe indicar la relacionada con los volúmenes almacenados en los embalses de cabecera (Entrepeñas y Buendía; $2474 \mathrm{hm}^{3}$ de capacidad de almacenamiento). Los volúmenes de trasvase dependen de las existencias conjuntas en estos reservorios a comienzos de cada mes, estableciendo diferentes niveles de explotación para los desembalses mensuales, con un máximo anual total de $650 \mathrm{hm}^{3}$ en cada año hidrológico.

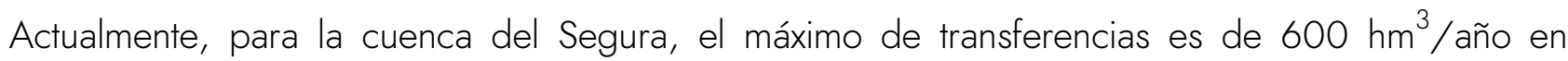
origen (540 hm $\mathrm{hm}^{3}$ en destino), destinándose $110 \mathrm{hm}^{3}$ a abastecimiento, $400 \mathrm{hm}^{3}$ para regadío y hasta $30 \mathrm{hm}^{3}$ por menores pérdidas a repartir entre los usuarios agrarios y abastecimiento de Almería en las Cuencas Mediterráneas Andaluzas (GALASA).

La modificación de las reglas de explotación del ATS ha supuesto un considerable incremento de los umbrales de agua embalsada en Entrepeñas-Buendía que establecen los niveles de emergencia y alerta, limitando su capacidad de funcionamiento en comparación con las exigencias anteriores, y ello por varios motivos. El primero, porque el nuevo umbral de "no trasvase" se eleva en $160 \mathrm{hm}^{3}$, tanto en la reserva embalsada en el sistema Entrepeñas-Buendía, que crece a $400 \mathrm{hm}^{3}$, como en la curva mensual de existencias que sirve para decretar las condiciones hidrológicas excepcionales (Real Decreto 2530/1985), lo que mermaría la flexibilidad de explotación del ATS cuando concurran situaciones de intensa y prolongada sequía en el Sureste Ibérico. Además, los mismos mecanismos atmosféricos y pluviométricos que provocan estas sequías en la cabecera del Segura también afectan a la del Tajo, lo que agrava sus efectos en la cuenca receptora al reducirse las transferencias (Gil, 2016).

En segundo lugar, otro factor determinante a considerar es la nueva asignación de recursos que soportarán los embalses de la cabecera del Tajo, y que el Modelo del Eje del Tajo estimó en 230,82 $\mathrm{hm}^{3} / a n ̃ o$, en el tramo comprendido entre Bolarque y Aranjuez. La presión sobre los recursos hídricos de la cabecera se incrementó notablemente en el anterior Plan Hidrológico de la cuenca del Tajo (2009-2015), al incluirse nuevas demandas para abastecimiento de las Mancomunidades Algodor y Girasol $\left(20 \mathrm{hm}^{3}\right)$, Sagra Alta y Baja $\left(20 \mathrm{hm}^{3}\right.$ ) y Canal de Isabel II $\left(60 \mathrm{hm}^{3}\right)$. En gran medida, este fuerte incremento de la demanda, con $100 \mathrm{hm}^{3} /$ año, respondía al incremento del consumo de agua potable que se preveía hace una década para atender nuevos y notables desarrollos urbanísticos en la zona sur del Área Metropolitana de Madrid y en comarcas como la Sagra (Toledo). En este sentido, cabe hacer notar que en el nuevo Plan Hidrológico de la 
cuenca del Tajo (2015-2021) se argumenta que el fuerte crecimiento demográfico de la Comunidad de Madrid y Castilla-La Mancha debe ser abastecido desde recursos regulados en la cabecera (embalses de Entrepeñas y Buendía), por carecer éstos de otras posibilidades. En dicho plan se recoge que las demandas de agua en la cabecera del río Tajo se incrementaran entre 2015 y 2033 en $184 \mathrm{hm}^{3}$, especialmente las demandas urbanas al pasar de 741 a $931 \mathrm{hm}^{3}$ y las industriales de 42 a $61 \mathrm{hm}^{3}$.

Cabe indicar que el abastecimiento de la Mancomunidad de la Sagra Alta y de gran parte del norte de Toledo es gestionado desde el año 2004 por la entidad pública Aguas de Castilla-La Mancha (ACLM) que depende de un sistema de distribución $(260 \mathrm{~km}$ ) con origen en el Embalse de Picadas (río Alberche), cuyos recursos son potabilizados en la planta de Valmojado. Sin embargo, para atender los fuertes crecimientos urbanísticos previstos en la Sagra, a partir de 2006, se iniciaron unas obras de conexión con el embalse de Almoguera, situado sobre el Tajo en la provincia de Guadalajara, con una inversión aproximada de 100 millones de euros. A pesar de que con el nuevo sistema de abastecimiento de Picadas se habían garantizado los consumos de la comarca, todos los nuevos proyectos residenciales quedaban supeditados a la nueva conexión con el embalse de Almoguera y con el Tajo. Sin embargo, la crisis de la construcción abocó al fracaso la mayoría de esas promociones inmobiliarias cuya garantía de suministro dependía de la conexión con Almoguera. Uno de los ejemplos locales más notables de los efectos de la crisis inmobiliaria en la Sagra se encuentra en el municipio de Seseña (22 992 hab.), donde se preveía la construcción de unas 13500 viviendas, de las que finalmente se construyeron unas 5000, no sin enormes dificultades para su venta y ocasionando graves pérdidas económicas a las entidades bancarias que financiaron el proyecto. En la actualidad todo el suministro de agua potable de la Mancomunidad de la Sagra Alta se atiende sin dificultad desde el embalse de Picadas que, según el dato que ofrece el Plan Especial de Sequía de la cuenca del Tajo (2017), la demanda es de 23,76 hm²/año para el Sistema Picadas CLM.

Un planteamiento similar al anterior, reforzado además por una tendencia global de incremento sostenido del consumo de agua potable hasta el año 2005, en el Área Metropolitana de Madrid, justificaba la conexión del Canal de Isabel II con el río Tajo, en el Azud de Valdajos, para alimentar la nueva ETAP de Colmenar de Oreja, que incorpora ultrafiltración y desalinización para corregir las carencias de calidad del agua del Alto Tajo. De hecho, esa decisión supuso un giro radical en la estrategia histórica de captación y transporte de agua potable por parte del Canal de Isabel II, desde su creación en 1858, que siempre había apostado por los recursos de agua de extraordinaria calidad y elevada garantía de suministro de la Cordillera Central. Esa decisión se adoptó en el contexto de la intensa sequía de 2004/05-2008/09, con la solicitud por parte del Canal de Isabel II de una concesión de $60 \mathrm{hm}^{3}$ desde el río Tajo, que se tramitó entonces al 
amparo del Real Decreto Ley 14/2009, de 4 de diciembre, por el que se adoptan medidas urgentes para paliar los efectos producidos por la sequía en determinadas cuencas hidrográficas.

\subsection{Sustitución progresiva de las transferencias con las desalinizadoras del Programa} A.G.U.A.

Desde 2004, con la imposición del Programa A.G.U.A. (Real Decreto-Ley 2/2004, convertido luego en la Ley 11/2005, de 22 de junio que modificaba la Ley 10/2001, del Plan Hidrológico Nacional), la contribución del ATS descendió notablemente, situándose por debajo de la dotación de $131 \mathrm{hm}^{3} /$ año que tenía asignada la Mancomunidad de los Canales del Taibilla (MCT), organismo público que gestiona el suministro urbano de agua en alta en el sureste peninsular (área receptora del trasvase) (Hernández-Mora, 2017). Al margen de la incidencia que tuvo la sequía de 2004/05-2008/09, en dicha reducción se dejó sentir la nueva orientación de la política hidráulica surgida del Programa A.G.U.A. que pretendía reducir la participación estratégica de los principales trasvases en las regiones mediterráneas, mediante su sustitución con la producción de agua desalinizada (Rico, 2010; 2016). Dicho objetivo fue recogido de forma explícita en la "Disposición adicional primera" de la Ley 11/2005, de 22 de junio, de modificación del Plan Hidrológico Nacional, donde se asumía que los volúmenes de agua proporcionados por el ATS a Murcia, Alicante y Almería, podrían verse reducidos a medida que se completasen las nuevas desalinizadoras previstas en el Programa A.G.U.A. Este planteamiento fue recogido en los contenidos de los nuevos Planes Hidrológicos de cuenca del Tajo, Segura, y Júcar, del anterior ciclo de planificación (2009-2015) y del actual (2015-2021). Por tanto, las normativas de dichos planes han incluido determinaciones que por un lado asumen la reducción de las transferencias del ATS y por otro, impulsan el uso de las desalinizadoras construidas mediante el Programa A.G.U.A.

En 2004, antes de la derogación del Trasvase del Ebro con el Real Decreto-Ley 2/2004 que dispuso la promulgación del Programa A.G.U.A., el Ministerio de Medio Ambiente había previsto el desarrollo de un plan de desalinización para garantizar el suministro de agua de la MCT que, se basaba en la construcción de 4 plantas con una capacidad total de $80 \mathrm{hm}^{3} /$ año. Fruto de este Plan, la desalinizadora del Canal de Alicante I $\left(24 \mathrm{hm}^{3}\right.$ ) entró en funcionamiento en 2003 y junto a la planta de San Pedro del Pinatar I $\left(24 \mathrm{hm}^{3}\right)$, en funcionamiento desde 2006, podrían aportar en torno a $48 \mathrm{hm}^{3} /$ año. Con las actuaciones previstas en el Plan Hidrológico Nacional (2001), la MCT ya había previsto alcanzar para 2007 la capacidad de $80 \mathrm{hm} 3$ /año, a partir de la ampliación de las plantas citadas y la construcción de otra nueva en Valdelentisco (Cartagena). Con el Programa A.G.U.A., el Ministerio de Medio Ambiente planteó incrementar todavía más la participación de la desalinización en el suministro de agua potable a la MCT con la construcción de las plantas de San Pedro del Pinatar II (24 hm³/año) y Alicante II (24 hm³/año), que entraron en servicio en 2006 y 2008, respectivamente. Por otro lado, la MCT también puede hacer uso de las desalinizadoras de Águilas $\left(60 \mathrm{hm}^{3}\right)$, Valdelentisco $\left(50 \mathrm{hm}^{3}\right)$ (Región de Murcia) y Torrevieja $\left(80 \mathrm{hm}^{3}\right.$ ) (provincia de 
Alicante), construidas por la empresa pública Acuamed a través del Programa A.G.U.A. En estas plantas, que suman casi unos $200 \mathrm{hm}^{3} /$ año de capacidad total, se han invertido 792 millones de euros con una participación de 166 millones de euros de fondos europeos (el 20,9\% de la inversión total) (Morote et al., 2017a).

Figura 1. Recursos hídricos utilizados por la MCT (1989-2016)

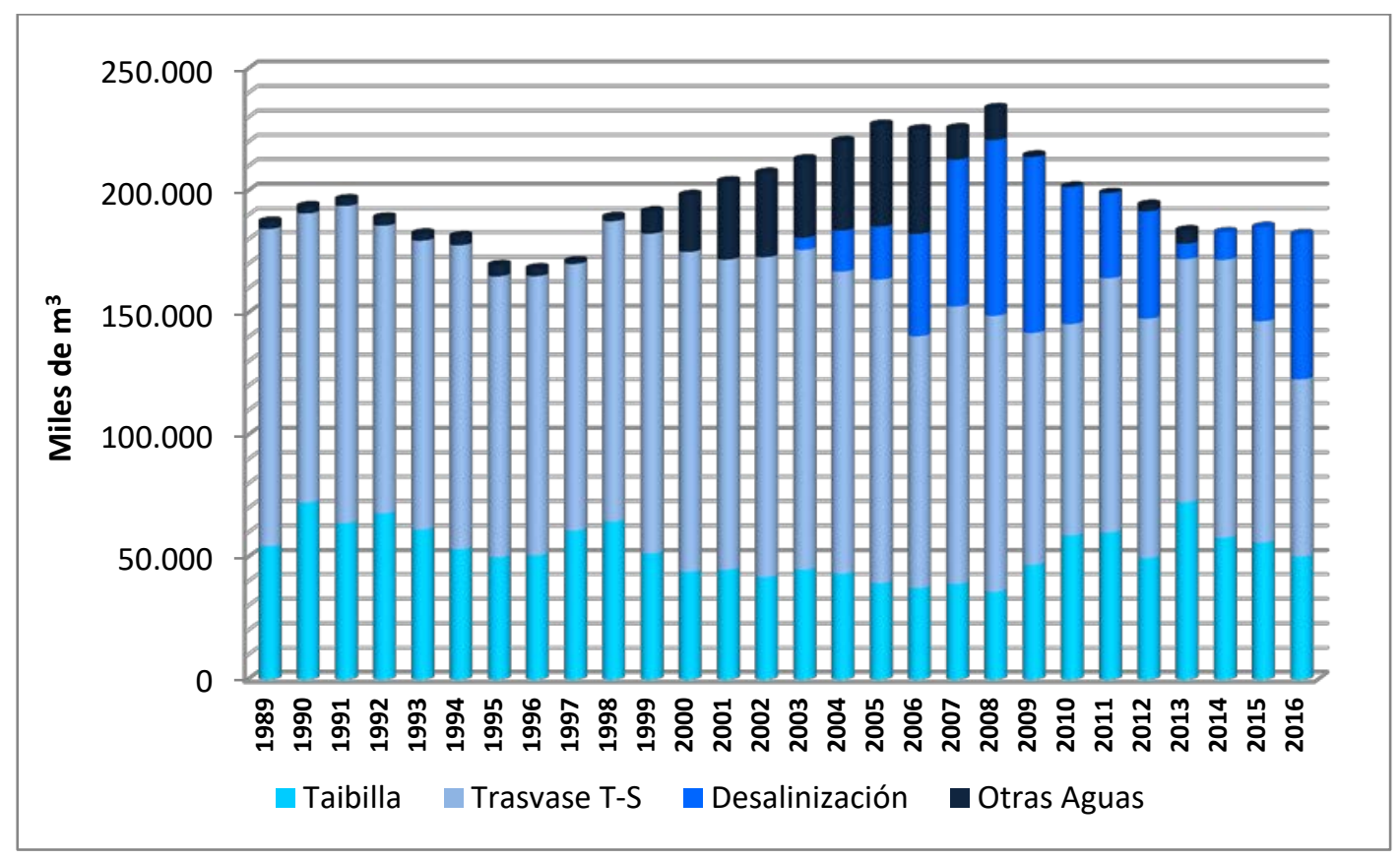

Nota: cabe indicar que desde mayo de 2017 no ha habido volúmenes transferidos del ATS por su cierre temporal.

Fuente: elaboración propia a partir de Mancomunidad de los Canales del Taibilla (2017).

Tras estas actuaciones la MCT suma una capacidad de producción cercana a $96 \mathrm{hm}^{3} /$ año, que ha crecido a $170 \mathrm{hm}^{3} /$ año con el Programa A.G.U.A, al sumar el $45 \%$ de la capacidad (200 hm³/año) de las plantas construidas por Acuamed en Águilas, Torrevieja y Valdelentisco. Sin embargo, la reducción de la demanda urbana durante la última década en el área atendida por la MCT (una reducción del agua suministrada del 3,15\% desde 2011) (190 hm³) (Figura 1) propició que la capacidad de oferta de agua desalinizada fuese muy superior a las necesidades actuales de suministro. En 2007, los estudios de demanda realizados por la MCT y la Confederación Hidrográfica del Segura preveían que en el año 2018 se habrían construido 650000 nuevas viviendas. Ello elevaría el consumo de agua potable a $340 \mathrm{hm}^{3} /$ año y haría necesario disponer de una capacidad de producción de agua desalinizada superior a $80 \mathrm{hm}^{3} /$ año para completar las fuentes convencionales. Por dicho motivo se redujo la producción en las plantas de la MCT durante los años 2008 y $2009\left(72\right.$ hm³ $^{3}$ ) (máximo histórico), a 6,2 hm³ en 2013, si bien, en 2016 ésta ha vuelto a aumentar a 59,5 $\mathrm{hm}^{3}$ debido a la reducción de los aportes del Taibilla y del ATS, en gran medida con agua desalinizada producida en las 4 plantas propias que tiene la MCT y plantas construidas con el Programa A.G.U.A. (Águilas, Valdelentisco y Torrevieja). De media, las fuentes 
de suministro de la MCT (1989-2016), por orden de importancia son: ATS (57\%) y en segundo lugar los propios recursos del río Taibilla (26\%), mientras que la desalinización, tras su incorporación en 2003, representa de media desde ese año el 18 \% del total de los recursos proporcionados. Sin embargo, tras el cierre del ATS entre mayo de 2017 y marzo de 2018, la desalinización ha aportado, por ejemplo, en 2017, el 44,08 \% del agua suministrada para usos urbanos en la región del sureste peninsular y en ciudades como Alicante, prácticamente el 70 \% del agua suministrada ha sido desalinizada. Por lo tanto, cabe hacer notar que, en gran medida, si los recursos superficiales (Taibilla y ATS) se ven mermados ante episodios de sequía, la producción de agua desalinizada se incrementa para hacer frente a esta reducción de caudales disponibles, haciendo del agua desalinizada un recurso alternativo, especialmente cuando no estén garantizados los convencionales (a pesar de su mayor coste), pero estratégico para paliar los efectos de los episodios de sequía (Morote et al., 2017b).

Es de resaltar que la MCT no tenía previsto que la desalinización contribuyese con más del 30\% al conjunto de recursos que distribuye. En primer lugar, por su elevado coste económico, muy superior al de otras fuentes de suministro (Figura 2); y en segundo término, porque técnicamente habría que modificar la red de captación y distribución actual, para cubrir áreas de uso que son atendidas con recursos del Taibilla y ATS. Sin embargo, la sequía que padeció gran parte de España y, concretamente, la cabecera del Tajo, conllevó que desde mayo de 2017 hasta marzo de 2018 los volúmenes almacenados en Entrepeñas y Buendía se situasen por debajo del umbral de no trasvase $\left(400 \mathrm{hm}^{3}\right)$. Este hecho ha repercutido en que actualmente la desalinización en el sureste peninsular se haya convertido desde la primavera de 2017 en una fuente ordinaria en el espacio litoral, garantizando el suministro de agua para usos urbanos y evitando así los cortes de suministro. Durante el cierre temporal del ATS, la gran mayoría de las plantas de la MCT funcionaron casi al $100 \%$ de su capacidad lo que demuestra que este recurso, controvertido por las desventajas que ofrece (Rico, 2010), a día de hoy ha pasado a convertirse en un recurso estratégico durante episodios de sequía.

Sin embargo, el elevado coste del agua desalinizada impide que se generalice como una fuente ordinaria de suministro en usos agrícolas. En la desalinizadora de Torrevieja, Acuamed intentó recabar el apoyo de los regantes ofreciéndoles agua desalinizada para riego a $0,30 € / \mathrm{m}^{3}$ (hasta el año 2017), es decir, muy por debajo del coste final producción que en el Informe de Viabilidad, realizado en 2006, ya se estimaba en $0,58 € / \mathrm{m}^{3}$. Con este precio político, los regantes del ATS han decidido adquirir alrededor de $40 \mathrm{hm}^{3} /$ año de dicha desalinizadora para paliar los efectos de la reducción de volúmenes trasvasados por efecto de la actual sequía, asumiendo un coste muy superior al que pagan actualmente por el agua de la cabecera del Tajo, que asciende a 0,09 $€ / \mathrm{m}^{3}$ (Figura 2). No obstante, la estrategia que ha intentado seguir Acuamed en las desalinizadoras de Torrevieja, Valdelentisco y Águilas para suministrar agua desalinizada para riego 
a precios inferiores al coste real de producción tropieza con varios inconvenientes. En primer lugar, la subvención de tarifas no garantiza que pueda generalizarse la desalinización de agua marina en los regadíos murcianos y valencianos, ya que son muy pocos los cultivos que pueden asumir precios superiores a $0,30 \circ 0,42 € / \mathrm{m}^{3}$. Y por otro lado, el déficit de tarifa en el agua desalinizada para riego habría de ser repercutido a los usuarios de abastecimiento, principalmente la MCT, que tiene toda la demanda garantizada con el ATS, río Taibilla y sus propias desalinizadoras que suman una capacidad de producción de $96 \mathrm{hm}^{3} /$ año.

Figura 2. Comparación del precio del agua $\left(€ / \mathrm{m}^{3}\right)$ y consumo de energía $\left(\mathrm{kWh} / \mathrm{m}^{3}\right)$, de las diferentes fuentes de suministro de la MCT (2017)

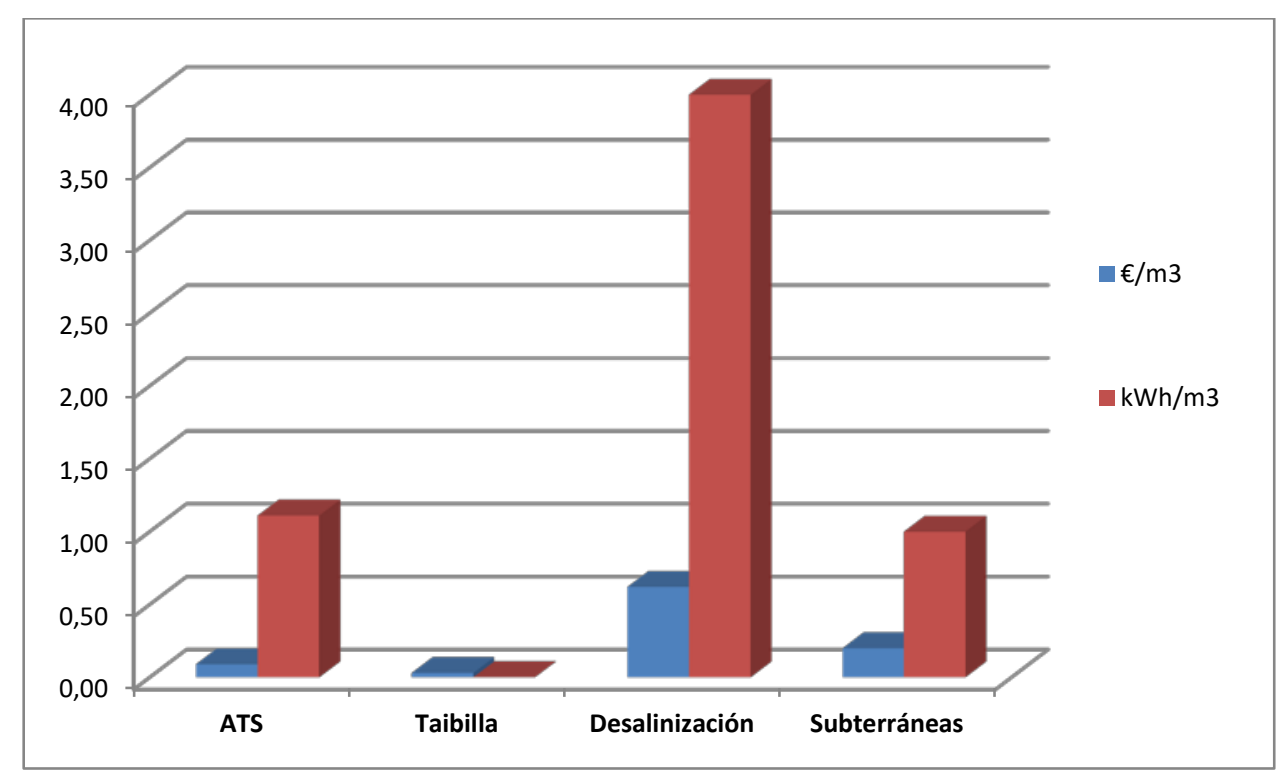

Nota: Para el caso de las aguas subterráneas se ha tenido en cuenta las extracciones de pozos de 200 metros de profundidad; para la desalinización se ha calculado el dato medio de las plantas de la MCT; y para las aguas del río Taibilla un consumo de energía de $0 \mathrm{kWh} / \mathrm{m}^{3}$ ).

Fuente: Mancomunidad de los Canales del Taibilla (2017)

\subsection{Efectos de las nuevas reglas de explotación en el funcionamiento del ATS}

Las nuevas reglas de explotación del ATS establecidas en la disposición adicional decimoquinta de la Ley 21/2015, de 20 de julio, de Montes y en el Real Decreto 773/2014, de 12 de septiembre han significado que el umbral mínimo de "no trasvase" se eleve de 240 a $400 \mathrm{hm}^{3}$ cuando se alcance este volumen en los embalses de Entrepeñas y Buendía. En la Tabla 3 se han reflejado los datos mensuales de volumen almacenado en cabecera desde octubre de 2004 a septiembre de 2018, y el nivel de explotación que hubiera existido de estar vigentes las nuevas reglas con el umbral de "no trasvase" de $400 \mathrm{hm}^{3}$. En este sentido, conviene subrayar que durante ese periodo el ATS hubiera dejado de funcionar durante 59 meses (de un total de 168, es decir el 35,11\% de este periodo) al situarse el volumen embalsado por debajo de los $400 \mathrm{hm}^{3}$. Sin embargo, de no 
estar vigentes estas nuevas normas de explotación, el ATS no habría funcionado durante 5 meses (de octubre de 2017 a febrero de 2018).

La media mensual del volumen almacenado en cabecera durante los últimos 20 años es de $703 \mathrm{hm}^{3}$ (desde octubre de 2004 a septiembre de 2018) pero esta cifra experimenta fuerte oscilación dependiendo de situaciones de sequía y de bonanza pluviométrica. Ello significa que, fácilmente, durante periodos de sequía, el volumen de agua almacenada se situará por debajo del umbral de no trasvase $\left(400 \mathrm{hm}^{3}\right)$ (Tabla 3). Este hecho ya ha ocurrido anteriormente (durante los años hidrológicos 2005/06-2009/10) pero estaba rigiendo un límite de "no trasvase" menos conservador y permitiendo transferencias cuando en cabecera había volúmenes almacenados entre 240-400 $\mathrm{hm}^{3}$ (Tabla 3). Ello pone de manifiesto que, de un total de capacidad de almacenamiento en Entrepeñas y Buendía de $2474 \mathrm{hm}^{3}$, con tan solo un $12 \%$ de agua embalsada se estaban efectuando transferencias a la cuenca del Segura. También cabe remarcar, como se puede observar en episodios pasados de intensa sequía y como el actual que, prácticamente, los volúmenes almacenados en los embalses de cabecera se situaran por debajo del umbral de 400 $\mathrm{hm}^{3}$ durante periodos de tiempo de alrededor cinco años (dependiendo de la intensidad de la sequía). Por tanto, no habrá transferencias al sureste peninsular coincidiendo con estos episodios durante aproximadamente ese tiempo con lo que se tienen que buscar alternativas y soluciones para paliar esa reducción de transferencias.

Tras la dura sequía ibérica de principios de los noventa, la recuperación de reservas en Entrepeñas y Buendía, propiciados por los inviernos lluviosos de 1995 a 1997, y de 2000, permitió que el promedio de agua trasvasada desde el año hidrológico 1995/96 a 2004/05 aumentase a $504 \mathrm{hm}^{3} /$ año. En cambio, la fuerte sequía que afectó a la cabecera del Tajo, desde los años hidrológicos 2005/06-2008/09, redujo las entradas a dichos embalses que almacenaban a principios de febrero de 2008 un volumen de $297 \mathrm{hm}^{3}$, umbral muy cercano a la reserva estratégica en aquel momento de $240 \mathrm{hm}^{3}$, por bajo de la cual no se podía efectuar ningún trasvase. A partir de 2010, el funcionamiento del trasvase se normalizó de nuevo, con transferencias que sumaron $378 \mathrm{hm}^{3}$ y $386 \mathrm{hm}^{3}$ durante los años hidrológicos 2010/11 y 2011/12, respectivamente. Tan solo en el año hidrológico 2000/01, se alcanzaron los 600 hm ${ }^{3}$ previstos (límite máximo de trasferencia anual para el sureste peninsular) (Figura 4). Hasta entonces, para riego, nunca se habían alcanzado los $400 \mathrm{hm}^{3}$ correspondientes, con máximo de 377 para 1986/87. Desde que empezó a funcionar el ATS (1979), la media de las transferencias se ha situado en $336 \mathrm{hm}^{3} /$ año, siendo sólo ampliamente superior a esta cifra durante los periodos 1995-2004 y 2010-2014. Como se puede observar en la Figura 4, el destino de los usos de las transferencias del ATS desde 1979 hasta su cierre en mayo de 2017 son el 60,03\% para regadío (201 hm³/año) y el 36,55 \% para suministros urbanos de la MCT (122 hm³/año). Sin embargo, durante situaciones de sequía los suministros urbanos tienen prioridad. Por ejemplo, para el periodo 
2004/05-2008/09, el agua destinada para suministro urbano representó el 48,81\% $\left(136 \mathrm{hm}^{3} /\right.$ año) mientras que el agua para regadío se redujo al $37 \%$. Además, cabe hacer notar que durante este periodo se realizaron cesiones de derechos de agua (mercados de agua) entre las comunidades de regantes de la cuenca cedente y receptora representando el 12\% de los volúmenes trasvasados. Al contrario, durante ciclos de bonanza pluviométrica en cabecera, aumenta el volumen destinado para riego. Por ejemplo, durante el periodo 1999-2004 el 68 \% del agua transferida se destinó para regadío.

Tabla 3. Repercusión de las nuevas condiciones previstas en Real Decreto 773/2014, de 12 de septiembre (Memorándum). Existencias almacenadas en Entrepeñas y Buendía a principios de cada mes (octubre de 2004 a septiembre de 2018)

\begin{tabular}{|c|c|c|c|c|c|c|c|c|c|c|c|c|}
\hline Año hidrológico & oct. & nov. & dic. & en & feb. & mar. & abr. & mayo & junio & julio & ag. & sept. \\
\hline $2004 / 2005$ & 779 & 747 & 766 & 783 & 752 & 710 & 676 & 635 & 580 & 521 & 426 & 360 \\
\hline $2005 / 2006$ & 332 & 298 & 286 & 301 & 305 & 298 & 328 & 348 & 340 & 309 & 265 & 244 \\
\hline $2006 / 2007$ & 244 & 259 & 268 & 302 & 304 & 336 & 337 & 403 & 456 & 461 & 408 & 361 \\
\hline $2007 / 2008$ & 241 & 359 & 337 & 322 & 297 & 279 & 279 & 274 & 353 & 391 & 367 & 320 \\
\hline $2008 / 2009$ & 310 & 315 & 315 & 349 & 395 & 487 & 551 & 596 & 569 & 524 & 476 & 409 \\
\hline $2009 / 2010$ & 374 & 375 & 360 & 380 & 648 & 813 & 994 & 1095 & 1.166 & 1191 & 1195 & 1136 \\
\hline $2010 / 2011$ & 1111 & 1101 & 1.096 & 1105 & 1157 & 1207 & 1274 & 1305 & 1301 & 1281 & 1184 & 1110 \\
\hline $2011 / 2012$ & 1078 & 1073 & 1.058 & 1040 & 1033 & 999 & 962 & 928 & 901 & 838 & 723 & 629 \\
\hline $2012 / 2013$ & 590 & 590 & 596 & 566 & 579 & 629 & 712 & 940 & 991 & 978 & 882 & 797 \\
\hline $2013 / 2014$ & 719 & 727 & 723 & 697 & 715 & 880 & 894 & 856 & 798 & 724 & 662 & 604 \\
\hline $2014 / 2015$ & 536 & 543 & 552 & 532 & 535 & 569 & 581 & 586 & 527 & 468 & 421 & 360 \\
\hline $2015 / 2016$ & 331 & 332 & 330 & 315 & 346 & 434 & 504 & 575 & 627 & 586 & 544 & 474 \\
\hline $2016 / 2017$ & 438 & 437 & 417 & 429 & 422 & 443 & 442 & 393 & 354 & 329 & 293 & 256 \\
\hline $2017 / 2018$ & 236 & 238 & 233 & 235 & 238 & 266 & 467 & 668 & 691 & 702 & 656 & 614 \\
\hline $\begin{array}{c}\text { Media } \\
\text { (2004-2018) }\end{array}$ & 522 & 528 & 524 & 525 & 551 & 596 & 642 & 685 & 689 & 664 & 607 & 548 \\
\hline
\end{tabular}

Nota: Color rojo (Nivel 4), color naranja (Nivel 3), color verde (Nivel 2) y color azul (Nivel 1).

Fuente: Ministerio de Agricultura, Alimentación y Medio Ambiente (2018)

En relación con sequía de 2004/05-2008/09, la MCT pudo firmar una serie de acuerdos con la Comunidad de Regantes del Canal de las Aves, con 3678 ha y adscrita a la Zona Regable de los Canales de Aranjuez (Madrid), en la cual se integran también la Real Acequia del Tajo, Caz Chico y Azuda que reúnen unas 7400 ha y una dotación de riego cercana a los $12000 \mathrm{~m}^{3} / \mathrm{ha}$ principalmente para riego de maíz. El acuerdo de compra de agua permitió a la entidad cesionaria la adquisición de $35 \mathrm{hm}^{3} /$ año, a un precio de $0,28 € / \mathrm{m}^{3}$. Estos ejemplos revelan que durante una de las más duras, intensas y prolongadas sequías de las últimas décadas (2004/052008/09), las reglas de explotación que regían en aquel momento el funcionamiento del ATS, no comprometieron en ningún caso la garantía de suministro de los usuarios de la cuenca cedente. 
Figura 4. Volúmenes trasvasados por el Trasvase Tajo-Segura (1979-2017)

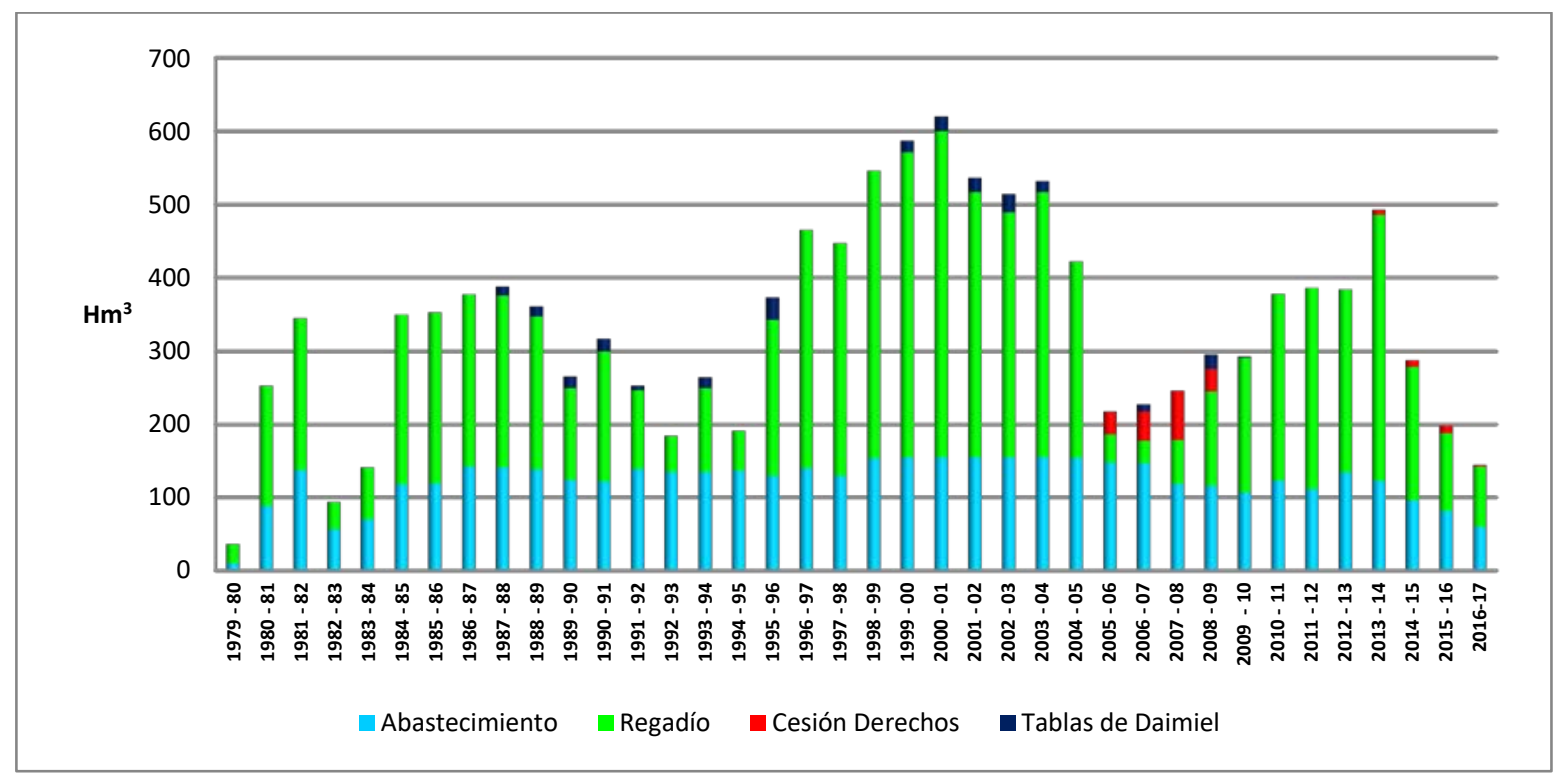

Nota: Cabe indicar que desde mayo de 2017 no ha habido volúmenes transferidos del ATS por su cierre temporal.

Fuente: elaboración propia a partir de SCRATS (2016)

Uno de los postulados argumentados por los detractores del ATS es que los cálculos originales del volumen de agua disponible en el Alto Tajo (Entrepeñas y Buendía) se inflaron en exceso. Además, ya en 1980, los recursos disponibles en la cabecera habían disminuido aproximadamente en un 47,5 \% ("efecto 80"), considerando en esa disminución, la reducción de las precipitaciones (lluvias e innivación) (Estevan et al., 2007). El mencionado efecto 80 hace referencia a la estimación de disminución de aportes desde la década de los ochenta para calcular los recursos hídricos disponibles en la planificación hidrológica.

Lo cierto es, que con las nuevas reglas de explotación para cumplir con el memorándum, las reservas en la cabecera del Tajo se situarán con gran frecuencia por debajo de los $400 \mathrm{hm}^{3}$ como ya ha sucedido recientemente desde agosto de 2015 a enero de 2016 y entre mayo de 2017 y marzo de 2018 (Tabla 3). En las tres últimas décadas se ha registrado ya una reducción a las aportaciones medias anuales $\left(\mathrm{hm}^{3} /\right.$ año) en todas las demarcaciones hidrográficas españolas. Comparando datos de aportación media entre 1996-2005, en relación con los valores medios del período 1940-1995, esta disminución se eleva al 14,3 \% para el conjunto del país, con valores más altos de esta reducción, por encima del $20 \%$, que se corresponden con las cuencas hidrográficas situadas en la mitad sur peninsular y el litoral mediterráneo. Para las dos cuencas hidrográficas que integran el sistema Tajo-Segura la reducción de aportaciones ha sido del -14,4 \% (Tajo, de 10.533 a 9.012 hm3/año) y del -38,2\% (Segura, de 817 a 505 hm³/año), siendo esta última demarcación la que habría experimentado una disminución mayor en el conjunto de cuencas hidrográficas españolas (Martín \& González, 2015). De manera que, desde que se diseñó el ATS a 
la actualidad, los recursos disponibles en una y otra cuenca hidrográfica han disminuido. Ello ha sido corroborado por diversos autores que ponen de manifiesto un claro cambio en los patrones de precipitación en los últimos veinte años en el sureste peninsular, con una reducción del 0-15\%, un incremento de los periodos secos y un descenso de los días de lluvia (Valdés et al., 2017).

A ello se unen los escenarios de cambio climático que en algunas regiones, como la cuenca del Mediterráneo, puede aumentar las tensiones por el uso del agua, si se cumplen las previsiones de reducción de lluvia y de incremento de la irregularidad pluviométrica previstas en la modelización climática (Olcina \& Vera, 2016). Por tanto, habrá que tener muy en cuenta estos escenarios para la adaptación de los territorios a las sequías y reducir la vulnerabilidad de estos frente a la reducción de aportes hídricos (Vargas \& Paneque, 2017). Según los planes de cuenca, en la cuenca del Segura se ha estimado una reducción de las aportaciones para el escenario 2033 del $5 \%$, mientras que en la cuenca del Tajo se estima en un $7 \%$. Además, este cambio, ya observado en el patrón estacional de las lluvias, está provocando una disminución de días de lluvia al año y una concentración mayor de éstos en otoño en detrimento de la primavera, las dos únicas estaciones del año lluviosas en el sureste ibérico, teniendo en cuenta que las primeras, en las regiones del litoral mediterráneo, son poco aprovechables, torrenciales pero súbitas y no almacenables (Olcina, 2016). En consecuencia, se estaría configurando un escenario a medio plazo en el que no habría agua disponible para la cuenca del Segura. Sin embargo, hasta el momento, parece ser que las iniciativas más importantes se relacionan con garantizar el suministro y abastecimiento de aguas con el incremento de la oferta y sin embargo, dejando de lado y, con un menor protagonismo, iniciativas conducentes a resolver esta cuestión desde la gestión de la demanda.

Como solución, diferentes organizaciones (regantes, diputaciones, ámbito académico, etc.), defienden aprovechar los recursos epigeos de la margen derecha del Tajo Medio para satisfacer las demandas urbanas de Madrid y Toledo para de esta manera, reducir la presión sobre la cuenca Alta del Tajo. Ello queda corroborado por las diferencias entre la cuenca Alta y Media donde los contrastes pluviométricos en esta última resultan acusados y trascendentes. En este sentido, las precipitaciones más cuantiosas, por encima de 2000 mm de media anual en los observatorios más favorecidos, corresponden a la vertiente meridional de la Cordillera Central, más abierta a las corrientes perturbadas atlánticas y de nivosidad abundante en los meses invernales. A medida que se avanza hacia el oeste, aproximándose al Atlántico y reduciendo el sotavento longitudinal, aumentan las precipitaciones, que se reducen hacia el centro de la cuenca y la divisoria meridional, donde algunas áreas reciben menos de 400 mm de precipitación media anual. Está acusada disimetría pluviométrica fundamenta la hidrológica, con marcada preponderancia del volumen de agua aportado por los tributarios de la margen derecha, en particular Jarama, Alberche, Tiétar y Alagón. De ahí, la existencia de dos cabeceras en la cuenca del Tajo: la hidrológica, en la Ibérica 
turolense, y la pluviométrica en la cara meridional de la Cordillera Central, distinción ésta que debiera ser básica para la planificación y ordenación de la cuenca (Gil, 2016).

Los regantes del Sindicato Central del Acueducto Tajo-Segura (SCRATS) han elaborado un informe de actuaciones viables a corto, medio y largo plazo para solventar la situación de escasez de recursos hídricos motivada por la actual sequía y cierre temporal del ATS (Tabla 4). Han determinado que para las áreas de regadío servidas por el SCRATS, de seguir con la misma superficie de regadío y mismos cultivos, sería necesario contar con un volumen complementario de recursos de unos $140 \mathrm{hm}^{3} /$ año adicionales a los valores medios que se reciben procedentes de la cabecera del Tajo pero, sin embargo, afirman que ninguna de estas alternativas tiene capacidad por sí sola para resolver por completo el problema, por lo que sería necesario combinar varias o bien recurrir a actuaciones a largo plazo. Por ejemplo, alguna de las medidas a corto y medio plazo que proponen son:

a) Incremento de la producción de las desalinizadoras existentes en la Demarcación Hidrográfica del Segura (Torrevieja, Valdelentisco y Águilas) (Programa A.G.U.A.):

1. El aumento de la producción posible con las instalaciones actualmente disponibles podría suponer en una primera fase un volumen adicional del orden de $70 \mathrm{hm}^{3} /$ año frente a la producción actual. Se requiere materializar el compromiso de la Administración de ampliar el suministro de energía eléctrica a la planta de Torrevieja, imprescindible para que se pueda alcanzar la producción de $80 \mathrm{hm}^{3} /$ año.

2. El segundo paso sería la ampliación de capacidad hasta el máximo previsto, es decir un incremento de $140 \mathrm{hm}^{3} /$ año frente a la producción actual, alcanzando los $260 \mathrm{hm}^{3} /$ año totales. La inversión estimada para este segundo paso es de 190 millones de euros. En el caso de la ampliación de las plantas desalinizadoras hasta su capacidad futura prevista, el coste de este incremento de producción (considerando tanto la repercusión de la inversión como el coste de explotación) ascendería a $0,65 € / \mathrm{m}^{3}$ en la desalinizadora de Torrevieja, $0,70 € / \mathrm{m}^{3}$ en la de Valdelentisco y $0,87 € / \mathrm{m}^{3}$ en la de Águilas. Estos valores son los de producción a pie de planta, y se verían incrementados en su caso por los costes de transporte en las redes existentes y en las nuevas conexiones previstas.

3. Se ha analizado también la posibilidad de que el suministro eléctrico sea realizado mediante energía solar fotovoltaica como apoyo al consumo de energía: es mejor ambientalmente y viable tanto técnica como económicamente y reducirá los costes de explotación (pero no significativamente el coste total). Para el caso de la planta de Torrevieja han comprobado su viabilidad técnica y económica, y supone una mejora ambiental.

4. Para su efectividad real, está ligada con la propuesta de conectividad entre las desalinizadoras y los embalses de regulación del postrasvase Tajo-Segura. 
5. El SCRATS ha solicitado a Acuamed que la producción disponible no comprometida de estas desalinizadoras se asigne a su demanda para cubrir el déficit existente. En cualquier caso no deberían asignarse a nuevas demandas no contempladas en el Plan Hidrológico del Segura.

b) Mejora de la conectividad entre las desalinizadoras y los embalses de regulación del postrasvase Tajo Segura:

1. La Conexión de la desalinizadora de Valdelentisco con el embalse de la Rambla de Algeciras. Esta actuación fue declarada obra de emergencia al amparo del Real Decreto $356 / 2015$ de 8 de mayo por el que se declara la situación de sequía en el ámbito territorial de la Confederación Hidrográfica del Segura, que fue prorrogada hasta el 30 septiembre de 2017 por el Real Decreto 335/2016, de 23 de septiembre, y se encuentra ya en ejecución, con un presupuesto máximo estimado de 5 millones de euros y una capacidad de transporte máxima estimada del orden de $14 \mathrm{hm}^{3} /$ año.

2. Conexión de los embalses de La Pedrera y Rambla de Algeciras. Una vez conectadas las plantas de Valdelentisco y Torrevieja con los embalses de Algeciras y La Pedrera, posibilitando así la producción continua y a plena capacidad de las plantas, se requiere conectar ambos embalses de forma que se cierre la red de conducciones principales con la mayor versatilidad y funcionalidad posible, repartiendo sus aguas eficazmente entre las zonas deficitarias. Con esta medida surge la necesidad de trasladar entre 33 y $47 \mathrm{hm}^{3} /$ año en el sentido de La Pedrera hacia Algeciras. Ello requiere para materializarse la construcción de una impulsión de aproximadamente $10 \mathrm{~km}$ con toma en el embalse de La Pedrera y estación de bombeo al pie del mismo, y de una conducción hasta la balsa al pie del embalse de la Rambla de Algeciras de unos $50 \mathrm{~km}$. El presupuesto estimado es de unos 90 millones de euros, y puede estar disponible a corto plazo si se aborda como emergencia al amparo del Real Decreto de sequía con vigencia prorrogada.

c) Cesión de derechos a través del ATS, procedentes de la Demarcación Hidrográfica del Tajo.

1. El máximo teórico a partir de la asignación de recursos del Plan Hidrológico de la cuenca del Tajo (2015-2021) es de $112 \mathrm{hm}^{3} /$ año, mientras que el máximo volumen anual realmente contratado ha sido de $31 \mathrm{hm}^{3}$. El coste máximo satisfecho está en el entorno de $0,20 \in / \mathrm{m}^{3}$.

2. El SCRATS solicita que la Administración proceda a la clarificación y regulación del procedimiento administrativo a seguir para la autorización de este tipo de contratos de cesión, indicando cuáles son sus condiciones y los supuestos que pueden impedir o menoscabar su celebración. 
Tabla 4. Actuaciones a corto, medio y largo plazo que propone el SCRATS para solucionar el aporte de recursos complementarios a las zonas abastecidas por el ATS

\begin{tabular}{|c|c|}
\hline Principales actuaciones a corto y medio plazo & Principales actuaciones a largo plazo \\
\hline \begin{tabular}{|ll}
$\checkmark$ & Incremento de la producción de las desalinizadoras \\
& existentes en la Demarcación Hidrográfica del Segura \\
& (Torrevieja, Valdelentisco y Águilas) para regadío \\
$\checkmark$ & Conexión de las desalinizadoras con los embalses de \\
& regulación de la zona (embalse de la Rambla de \\
& Algeciras y embalse de La Pedrera) \\
$\checkmark$ & $\begin{array}{l}\text { Cesiones de derechos a través del ATS, con origen } \\
\text { en la Demarcación Hidrográfica del Tajo }\end{array}$ \\
\end{tabular} & $\begin{array}{ll}\checkmark & \text { Derivación de recursos desde el Duero medio } \\
\checkmark & \text { Derivación desde el Tajo en el embalse de Azután } \\
\checkmark & \text { Derivación desde el Tajo en Toledo } \\
\checkmark & \text { Derivación de recursos en desembocadura del Ebro } \\
& \text { (hasta Segura) } \\
\checkmark & \text { Derivación de recursos desde el Ebro medio } \\
\checkmark & \text { Incremento de la capacidad de desalinización en la } \\
& \text { Demarcación del Segura. }\end{array}$ \\
\hline
\end{tabular}

Fuente: elaboración propia a partir de SCRATS (2017)

En cuanto a las medidas a largo plazo que el SCRATS propone, cabe indicar que se tratan de actuaciones no exentas de polémica por la controversia socio-política, económica y ambiental que puede surgir. Se tratan de medidas basadas en la continuación de la llamada "vieja política hidraúlica" con la construcción de trasvases intercuencas. Las principales medidas que proponen son las siguientes:

a) Derivación de recursos desde el Duero medio. El planteamiento es derivar desde el Duero aguas abajo de la confluencia de Pisuerga y Adaja y enlazar con el trazado planteado en la DT del PHN 2000 entre el Bajo Duero (Villalcampo) y el embalse de Entrepeñas. La transferencia desde el Duero medio hasta Entrepeñas tiene capacidad por sí sola para derivar el volumen de $250 \mathrm{hm}^{3}$ /año requerido en el ámbito del SCRATS con un coeficiente de sobredimensionamiento del orden de 1,2.

b) Derivación de recursos desde el Tajo en el embalse de Azután. Esta alternativa pretende incrementar el volumen aportado por el ATS hacia el sureste con recursos derivados desde el embalse de Azután que se incorporan al ATS a la altura de La Roda (Albacete). Asumiendo los datos y resultados obtenidos a partir del modelo de simulación elaborado por el Organismo de cuenca en el marco del PHC vigente, la transferencia desde el embalse de Azután hasta el ATS a la altura de La Roda, tiene capacidad por sí sola para derivar el volumen de $250 \mathrm{hm}^{3} /$ año requerido en el ámbito del SCRATS con un coeficiente de sobredimensionamiento del orden de 1,8. Esta toma permitiría asimismo derivar volúmenes mayores, del orden de $450 \mathrm{hm}^{3}$ con un coeficiente de toma de 2,1 .

c) Derivación de recursos desde el Tajo en Toledo. En esta alternativa los recursos se derivan del Tajo medio, ligeramente aguas abajo de Toledo y se incorporarían al ATS a la altura de La Roda. Permite utilizar el embalse de Finisterre sobre el río Algodor, ya existente y con una capacidad útil total de $133 \mathrm{hm}^{3}$, como elemento de regulación del volumen trasvasado si fuese necesario.

d) Derivación de recursos en desembocadura del Ebro (hasta la cuenca del Segura). Esta alternativa trata la derivación desde el Bajo Ebro aguas abajo de Tortosa hasta la conexión con el 
Canal de la margen derecha del Postrasvase Tajo-Segura a la salida del túnel del Cajal, aguas arriba del embalse del Mayés. Esta opción domina casi completamente las áreas deficitarias vinculadas al ATS, y la práctica totalidad de las zonas deficitarias del sureste español.

e) Derivación de recursos desde el Ebro medio. El SCRATS plantea la conexión de la Demarcación Hidrográfica del Ebro, partiendo de su tramo medio entre la derivación del Canal Imperial de Aragón y la confluencia del Ebro y el Jalón, con el Sistema de Cabecera de la Demarcación Hidrográfica del Tajo a través del conocido corredor del Jalón, aportando nuevos recursos al embalse de Entrepeñas que podrían ser derivados a través del ATS.

\section{Discusión: trasvases y desalinización, ¿la gran solución a la escasez de agua?}

La puesta en marcha de transferencias hídricas se convirtió en una de las alternativas que más conflictos socio-territoriales generó durante el pasado siglo entre cuencas emisoras y receptoras (Saurí \& del Moral, 2001). En España, el funcionamiento del ATS ha suscitado creciente polémica entre las regiones cedentes de la cuenca del Tajo y la receptora del Segura. Por una parte, los que se oponen a esta transferencia desde el centro de la península acusan a los usuarios de Almería, Murcia y Alicante de apropiarse de "su recursos" sin recibir nada a cambio, además de poner en riesgo su propio desarrollo socio-económico y la conservación del río por la reducción de caudales ecológicos. Ello, se ha debido, en parte, por la escasa decisión del Estado y de las respectivas autonomías y administraciones locales a la hora de impulsar decisiones que garanticen los distintos usos del agua en España (bien de interés público), con actuaciones que solucionen los problemas que genera su escasez, particularmente durante situaciones de sequía. En este sentido, un rasgo esencial en el desarrollo de la política del agua española durante la segunda mitad del siglo XX ha sido la rápida apuesta por una política de oferta solicitada por regantes, abastecimientos y empresas hidroeléctricas. Dichas partes, tienen diferentes intereses que condicionan la adaptación de una política hídrica a las nuevas demandas sociales y a las exigencias de la Directiva Marco del Agua (2000/60/CE). Por ello, se hace necesario diseñar mecanismos institucionales que combinen a largo y a corto plazo sin comprometer la adaptación a las nuevas realidades y cambios de decisión. Como señalan Hernández-Mora et al. (2014), la participación debería ser un elemento clave en un diseño institucional de las políticas hídricas, aunque tropieza con la dificultad de establecer marcos de cooperación entre los distintos usuarios. Además, se precisaría un cambio en las estructuras de gobernanza del agua, para hacer posible la armonización de los intereses nacionales con los regionales, concertando los distintos usos con el cumplimiento de las exigencias ambientales de la citada directiva.

Las posturas encontradas entre detractores y defensores del ATS se han intensificado, más aún si cabe durante el actual ciclo de sequía 2015-18, y a ello ha contribuido la aprobación de las 
nuevas reglas de explotación del ATS que se plantearon durante la tramitación del anterior Plan Hidrológico del Tajo (2009-2015). Esas reglas fueron recogidas en la Ley 21/2013 de 9 de diciembre, de Evaluación Ambiental; en la Ley 21/2015, de 20 de julio, de Montes; en el Real Decreto 773/2014, de 12 de septiembre, por el que se aprueban diversas normas reguladoras del trasvase, con los acuerdos suscritos en el llamado "Memorándum"; y finalmente, se han reflejado en el Real Decreto 1/2016, de 8 de enero por el que se aprobaba el actual Plan Hidrológico de la cuenca del Tajo (2015-2021). En apretada síntesis, el escenario actual establece diferentes niveles de explotación destacando que el Nivel 4, prohíbe las transferencias cuando las reservas en cabecera se sitúen por debajo de $400 \mathrm{hm}^{3}$, cuando anteriormente se situaba en $240 \mathrm{hm}^{3}$.

El cambio tan profundo de las reglas de explotación del ATS (Art. 26 de la Propuesta de Proyecto del anterior Plan Hidrológico de la cuenca del Tajo, 2009-2015), se ha justificado por diversos motivos. Uno de ellos se debe por el cumplimiento de los principios de la Directiva Marco del Agua (2000/60/CE) en el que se establece un nuevo paradigma de la planificación hidrológica caracterizado por la incorporación al enfoque tradicional de la satisfacción de la demanda, el de alcanzar el buen estado ecológico de todas las masas de agua. En definitiva, la nueva planificación trata de compatibilizar las distintas necesidades de la sociedad actual con una gestión racional que permita el desarrollo sostenible y garantice el buen estado ecológico de los sistemas naturales. De esta manera, con este nuevo marco de referencia se cumpliría con las directrices de la DMA al establecer unos valores suficientes de caudales ecológicos.

En segundo lugar, además, en reconocimiento a la prioridad de la cuenca cedente se ha incrementado significativamente la reserva de "no trasvase" en los embalses de Entrepeñas y Buendía para atender futuros incrementos de las demandas, principalmente de las urbanas en el sistema de la cabecera del Tajo que se ha estimado en $184 \mathrm{hm}^{3}$ para 2033 según el actual Plan Hidrológico de la cuenca del Tajo (2015-2021). Asimismo, la modificación de las normas reguladoras del ATS, aprobadas con el Real Decreto 773/2014, cumpliría con el objetivo de "proporcionar una mayor estabilidad interanual a los envíos, minimizando la presentación de situaciones hidrológicas excepcionales", imponiendo un mayor control de las aguas trasvasadas en destino, con el establecimiento de consumos mensuales de referencia (art. 3). También se establecen los "desembalses de referencia" (art. 4), a efectuar desde la presa de Bolarque, con caudales mensuales que oscilarían de $6,9 \mathrm{~m}^{3} / \mathrm{s}$ (enero) a $22,4 \mathrm{~m}^{3} / \mathrm{s}$ (julio) para atender las necesidades ambientales y de consumo del sistema de la cabecera del Tajo; y estos caudales podrían incrementarse en otros $2 \mathrm{~m}^{3} / \mathrm{s}$ adicionales, si el Canal de Isabel II tuviera que activar la toma de la presa de Valdajos.

En tercer lugar, cabe mencionar la nueva orientación de la política hidráulica surgida del Programa A.G.U.A. que pretendía reducir la participación estratégica de los principales trasvases en las regiones mediterráneas, mediante su sustitución con la producción de agua desalinizada y que ha 
sido recogido en los contenidos de los nuevos Planes Hidrológicos de cuenca del Tajo, Segura, y Júcar del anterior ciclo de planificación (2009-2015) y del actual (2015-2021). En relación con la desalinización, cabe sumar la controversia en torno a las luces y sombras que hasta el momento ofrecían como, por ejemplo, la construcción e inversión de grandes plantas, muchas de ellas, sin funcionar o funcionando con un bajo rendimiento por falta de demanda (Morote et al., 2017a; 2017b). De esta manera, la reducción de las transferencias posibilitaría la puesta en marcha de estas desalinizadoras (como ya ha sucedido durante el cierre temporal del ATS en el que gracias a la desalinización se han garantizado los suministros urbanos sin problemas) y, finalmente, se mitigarán las reivindicaciones y controversia social y política desde la cuenca cedente con la adopción de unas normas más conservadoras y justas para estos últimos.

Como se recoge en el trabajo de Juárez (1991) las expectativas generadas por el ATS fueron tales que, en palabras de los técnicos y las autoridades hidráulicas, esta infraestructura triplicaría la zona regable, resolvería definitivamente el problema del abastecimiento e impulsaría el desarrollo industrial y turístico de las zonas receptoras. Éste se trata de un tema clave, el desbordamiento de las previsiones de la planificación que el ATS iba a desencadenar. Otros autores como Martínez y Esteve (2000), tras dos décadas de funcionamiento del ATS, pusieron de manifiesto que la situación deficitaria de la cuenca del Segura era mucho más grave que la existente inicialmente ya que el trasvase ha contribuido a generar una sequía estructural creciente y a aumentar los riesgos de desertificación a través de la creación de grandes expectativas y de la expansión de la demanda agraria. Estos autores alertaban del grave problema que representaba el déficit estructural existente ya a finales de los sesenta y principios de los setenta, lo cual incluía la consolidación de los regadíos alegales creados al margen de toda autorización administrativa y, en segundo lugar, la expansión de nuevas zonas regables. El resultado final es que las expectativas generadas por el ATS han generado un déficit por una doble vía: 1) los recursos trasvasados han sido notoriamente inferiores a los máximos legales; y 2) la superficie de regadío se ha incrementado muy por encima de la considerada inicialmente, aun suponiendo garantizado un trasvase con los volúmenes máximos.

Con la adopción de las nuevas normas de explotación, el funcionamiento del ATS está condicionando a ciclos de sequía. Del análisis que se puede extraer de histórico de almacenamiento en cabecera es que cada cierto tiempo (cada 8-10 años) el trasvase se cerrará a consecuencia de episodios cíclicos de sequía con por un periodo de tiempo aproximado de 4-5 años, teniendo en cuenta episodios pasados y el actual. Ante esta situación, la desalinización ha pasado a convertirse en un pilar fundamental y estratégico para el abastecimiento y suministro urbano y, considerado como una fuente hídrica ordinaria durante ciclos de intensa y prolongada sequía. Por tanto, debería cambiar la percepción en torno a la dependencia de las transferencias del ATS en el sureste peninsular y pensar en un nuevo enfoque y finalización del "viejo paradigma 
hidráulico" mientras las nuevas normas de explotación estén vigentes. Es decir, el ATS sólo será una fuente hídrica disponible durante años de bonanza pluviométrica en la cabecera del Tajo y la desalinización pasará a convertirse cada vez más en una fuente ordinaria y estratégica, especialmente durante episodios de sequía.

Para la cuenca del Segura, donde hay reconocido un déficit de $400 \mathrm{hm}^{3}$ /año (Plan Hidrológico de la cuenca del Segura, 2015-2021) (teniendo en cuenta los aportes del ATS y de las fuentes no convencionales), se reclama que alcance una autosuficiencia de recursos que estaría posibilitada por el Programa A.G.U.A. que ha impulsado la desalinización a gran escala. Con una optimización amplia de los recursos no convencionales (reutilización de aguas depuradas regeneradas y desalinización) y con una gestión más eficiente de la demanda, la garantía de suministro en la cuenca del Segura podría estar comprendida entre 275-575 hm³/año (dependiendo de coyunturas pluviométricas). Además, cabe incidir que son cálculos referidos a la situación de explotación actual, por ello, cualquier incremento de los diferentes usos supondría mayores necesidades de agua. Por otro lado, cabe plantear tres cuestiones decisivas a la hora de concretar el déficit de agua existente y su distribución espacial, como son: 1) la infradotación de regadíos; 2) la restauración de acuíferos sobreexplotados (recarga artificial); y 3) la garantía de caudales ecológicos en humedales y ríos (Morales et al., 2005).

Sin embargo, durante los últimos años, la gran mayoría de las desalinizadoras, han estado inactivas o funcionando al 30\% de su capacidad, por las noches o fines de semanas (debido al elevado coste de la energía y a la escasa demanda) (March et al., 2014; Sywngedouw y Williams, 2016; Morote et al., 2017a). La ejecución del Programa A.G.U.A. (1100 millones de euros, siendo 200 millones procedentes de fondos europeos) (Morote et al., 2017b) no logró alcanzar las expectativas esperadas, debido al alto coste de este recurso y al exceso de oferta existente, justificado por unos estudios de viabilidad que preveían un incremento de la demanda de agua potable, del número de viviendas construidas y población atendida. Lejos de estas expectativas, con el estallido de la burbuja inmobiliaria y crisis económica (2008), no sólo no han crecido las demandas, si no que desde 2004/05 se ha producido un descenso del gasto de agua gracias a las diferentes medidas adoptadas por los usuarios y organismos y empresas encargadas del suministro de agua, tanto en alta como en baja (Gil et al., 2015; Morote et al., 2016).

La sustitución completa del ATS con agua desalinizada es técnica y económicamente inviable (por lo menos para regadío y áreas urbanas de interior). Por ejemplo, en los estados más avanzados del mundo en materia de gestión y protección de recursos de agua, se emplean métodos innovadores basados en el "Análisis del Ciclo de Vida", para valorar con criterios de eficiencia ambiental, económica y energética las diferentes alternativas de suministro de agua. Este método se ha aplicado en los EE.UU. durante los últimos años para evaluar la eficiencia de los trasvases de agua frente a la desalinización. Así, en el Estado de California la desalinización constituye una alternativa 
considerada mucho menos segura y de mayor impacto ambiental que los trasvases de agua (Horvath y Stokes, 2011). Los costes de operación de los trasvases Colorado River Aqueduct y State Water Project son inferiores a $0,19 € / \mathrm{m}^{3}$, mientras que la desalinización arroja costes superiores a $0,60 € / \mathrm{m}^{3}$; de ahí que esta fuente resulte minoritaria y de escasa aceptación social en relación con otras alternativas de suministro como los trasvases. El agua disponible en el Estado de California es $45.068 \mathrm{hm}^{3} /$ año, la desalinización tan sólo aporta el $1 \%$ (398 hm²/año), mientras que los trasvases movilizan $18872 \mathrm{hm}^{3} /$ año, es decir, el $32 \%$ de los recursos (Horvath \& Stokes, 2011). También se puede observar la comparación entre estos recursos en relación con la percepción que tiene la población en el caso español. Por ejemplo, según el estudio de March et al., (2015), en la provincia de Alicante el análisis de la percepción de la población en vinculación con la preferencia de las distintas fuentes de suministro revela que para incrementar la oferta de agua en esta provincia, el recurso más valorado por orden de prioridad fue: potenciar el uso de las aguas pluviales; aumentar el agua trasvasada del ATS; realización del Trasvase del Ebro; utilización de aguas regeneradas depuradas; y el uso de agua desalinizada (debido a su alto coste).

En el sureste peninsular, según algunos autores, la desalinización se ha pretendido convertir en la gran solución, si bien, de momento resulta económicamente más cara e inviable para los usos agrícolas si no se aplica un precio político (Swyngedouw \& Williams, 2016). La desalinización ha adquirido valor como recurso estratégico (especialmente para el suministro urbano) para paliar coyunturalmente la disminución de otros recursos (como ya sucedió con el propio río Taibilla o en la actualidad con el ATS), pero no puede tratarse, hasta el momento, de un recurso sustitutivo del ATS para usos agrarios. Y ello, se debe por 4 factores principales (Tabla 5):

1) Elevado coste de la desalinización (consumo energético y precio del agua). Este recurso, hasta el momento, resulta económica y energéticamente inviable en comparación con el ATS, $(0,09 €$ frente a $0,60-1 € / \mathrm{m}^{3} ; 1,11 \mathrm{kWh}$ frente a $\left.4 \mathrm{kWh} / \mathrm{m}^{3}\right)$. Por ejemplo, la desalinizadora de Torrevieja, la más grande de Europa $\left(80 \mathrm{hm}^{3} / \mathrm{año}\right)$, durante 2017 estuvo funcionando al $30 \%$ de su capacidad, pero con tarifa subvencionada hasta 2017 al amparo de un Decreto de Sequía para usos agrarios (Morote et al., 2017a). Actualmente, cabe indicar que dicha planta está funcionando al $50 \%$ de su capacidad debido a que no tiene garantizado el suministro de energía para poder producir al 100\% situándose el coste del agua a 0,55 €/m ${ }^{3}$. Sin embargo, cabe insistir que desde Castilla-La Mancha se defiende que las desalinizadoras produzcan agua subvencionada (a un precio igual que la del ATS, a $0,09 € / \mathrm{m}^{3}$ ). Los usos urbanos sí que podrían asumir el precio de este recurso, sin embargo, no sucede igual para toda la agricultura que se práctica en el área dotada con aguas del ATS y, teniendo en cuenta que, el 37\% del total de esta superficie (54950 ha) se riega exclusivamente con estos recursos procedentes del Alto Tajo. Por ejemplo, las explotaciones que practican cultivos hortícolas de ciclo manipulado tienen una mayor capacidad para asumir los costes del agua desalinizada. No obstante, los regantes 
del SCRATS afirman que costes superiores a $0,30 € / \mathrm{m}^{3}$ mermarían la competitividad de determinadas explotaciones. Por ejemplo, las explotaciones de cítricos no podrían asumir ese coste y, todo ello, teniendo en cuenta que los cítricos ocupan una superficie de 61316 ha (el 50 \% aproximadamente de la superficie cultivada en el área regable del SCRATS).

2) Necesidad de construir una nueva red de distribución para transportar el agua para el riego, tanto a las zonas del litoral, prelitoral e interior. Por lo tanto, se necesitaría la construcción de conducciones y asumiendo un mayor coste de bombeo $\left(0,40 \mathrm{kWh} / \mathrm{m}^{3}\right.$ por cada $100 \mathrm{~mm}$ que se asciende de cota). Cabe tener en cuenta que habría que bombear el agua hasta zonas de regadío que utilizan agua del ATS a una cota de unos 300-400 m.s.n.m. Se trata, por tanto, de inversiones costosas para configurar una nueva red de distribución desde la costa al interior para entregar el agua en los regadíos del Valle del Guadalentín y piedemontes de las estribaciones béticas.

3) Durante el cierre del ATS en 2017-18, gran parte de la producción de las desalinizadoras del Programa A.G.U.A. se destinaron para abastecimiento (a excepción de Águilas). Por tanto, teniendo en cuenta que la media transferida anual para regadío desde 1979 se sitúa en 201 hm³ (aunque con un techo máximo de $400 \mathrm{hm}^{3}$ que se han alcanzado otros años hidrológicos), de seguir con el mismo modelo agrario y considerando la desalinización como un recurso sustitutivo, habría que incrementar la capacidad de producción de las plantas ya existentes, al igual que la construcción de otras nuevas para sumar una producción anual que el SCRATS ha estimado en $260 \mathrm{hm}^{3}$ a la capacidad instalada actualmente.

4) Calidad del agua (el problema del Boro). Las desalinizadoras de agua marina proporcionan un recurso de elevada calidad, si bien, con la excepción que representa la presencia de Boro, que alcanza valores superiores a $0,5 \mathrm{mg} / \mathrm{l}$, lo que resulta sumamente perjudicial para el riego de cítricos que, como ya se ha citado, en estos momentos ocupan el 50 \% de la superficie dotada con recursos del ATS.

Además, en relación con los aspectos ambientales, el litoral del sureste peninsular no siempre reúne condiciones favorables para implantar tomas directas de agua marina, ni para evacuar el agua de rechazo (salmuera). Ello ha obligado a adoptar distintas soluciones no exentas de dificultades técnicas en su construcción. Por ejemplo, en la planta de Alicante II se optó por un túnel de 1 km, paralelo a la costa, alimentado por 103 sondeos de 2 metros de profundidad, separadas a unos 10 metros entre sí e inclinados $30^{\circ}$ para atravesar una formación permeable en contacto directo con el mar. Y en la planta de San Pedro del Pinatar I (Región de Murcia), la toma se hace en la Playa de la Higuerita (Municipio del Pilar de la Horadada, provincia de Alicante), con 20 perforaciones horizontales de 450 metros de longitud en la zona de servidumbre del dominio público marítimo terrestre. Además, en la evacuación de la salmuera, para evitar daños a las praderas de Posidonia 
oceánica, también se ha tenido que recurrir a soluciones en ocasiones muy costosas (ver Rico, 2016).

\section{Tabla 5. Inconvenientes de la desalinización para poder sustituir las transferencias del ATS para regadío en la cuenca del Segura}

1) Elevado coste de la desalinización (consumo energético y precio del agua).

$\checkmark \operatorname{ATS}\left(0,09 € / \mathrm{m}^{3}\right)$ y desalinización $\left(0,60-1 € / \mathrm{m}^{3}\right)$

$\checkmark$ ATS $\left(1,11 \mathrm{kWh} / \mathrm{m}^{3}\right)$ y desalinización $\left(4 \mathrm{kWh} / \mathrm{m}^{3}\right)$.

2) Necesidad de construir una nueva red de distribución para transportar el agua para el riego, tanto a las zonas del litoral, prelitoral e interior.

$\checkmark$ Construcción de nuevas conducciones y asumiendo un mayor coste de bombeo $\left(0,40 \mathrm{kWh} / \mathrm{m}^{3}\right.$ por cada $100 \mathrm{~m}$ que se asciende de cota.

3) De seguir con el mismo modelo agrario y considerando la desalinización como un recurso sustitutivo, habría que incrementar la capacidad de producción de las plantas ya existentes, al igual que la construcción de otras nuevas.

4) Calidad del agua (el problema del Boro).

$\checkmark$ La presencia de Boro (valores superiores a $0,5 \mathrm{mg} / \mathrm{l}$ de agua desalinizada) resulta sumamente perjudicial para el riego de cítricos (el $50 \%$ de la superficie dotada con recursos del ATS)

Fuente: elaboración propia

Durante el cierre temporal del ATS las plantas de la MCT están funcionaron casi al $100 \%$ de su capacidad y suministrando más del 70 \% de los recursos disponibles en la franja litoral. Con este notable incremento de la producción de agua desalinizada en el último año, la MCT anunció un posible incremento actual del precio del agua $\left(0,69 € / \mathrm{m}^{3}\right)$ de continuar el periodo de sequía. Además, el Gobierno actual, que ha asumido la política del agua del anterior, ha puesto en marcha las desalinizadoras del Programa A.G.U.A. para compensar los recortes y el cierre actual del trasvase, y todo ello con una deficiente gestión financiera desde un primer momento que se ha visto salpicada por casos de corrupción (Caso "Acuamed"). Asimismo, tras la crisis inmobiliaria de 2008, tampoco se revisaron los proyectos de construcción de algunas desalinizadoras, claramente sobredimensionadas, para garantizar el suministro a grandes proyectos urbanísticos que se preveían en el litoral mediterráneo (Morote et al., 2017b). Es el caso de la planta de Muchamiel (Acuamed) (provincia de Alicante) que, con una capacidad de $18 \mathrm{hm}^{3}$ desde el otoño de 2016 se encuentra parada y sin demanda. Dicha planta entró en funcionamiento en junio de 2015 para suministrar $5 \mathrm{hm}^{3} /$ año a la comarca de la Marina Baja (principalmente a la ciudad de Benidorm) a través de la Conducción Rabasa-Fenollar-Amadorio pero, con las precipitaciones acaecidas durante el otoño de 2016 e invierno de 2017 los embalses de la Marina Baja se recuperaron, garantizando el suministro con recursos propios. Ante el excedente de agua embalsada, no se firmó el convenio con Acuamed que prolongaba la concesión de suministro de agua desalinizada desde esta desalinizadora. 
La Ley 11/2005, de 22 de junio, por la que se modifica la Ley 10/2001, de 5 de julio, del Plan Hidrológico Nacional, añadió un nuevo apartado 5 al artículo 46 del Texto Refundido de la Ley de Aguas, en el cual se establece que "con carácter previo a la declaración de interés general de una obra hidráulica, deberá elaborarse un informe que justifique su viabilidad económica, técnica, social y ambiental, incluyendo un estudio específico sobre la recuperación de costes". Así, la construcción de las desalinizadoras del Programa A.G.U.A. se acompañó de unos "Informes de Viabilidad de Proyectos", la mayoría de ellos realizados entre 2005 y 2007, en los cuales se justificaba la inversión pública en las desalinizadoras por la necesidad de atender el fuerte incremento del consumo de agua potable que se estaba produciendo las regiones mediterráneas. Se asumía que un volumen significativo del agua desalinizada iba a destinarse a garantizar las demandas generadas por los nuevos complejos residenciales turísticos previstos en todo el litoral mediterráneo español, antes del estallido de la burbuja inmobiliaria a partir de 2008. Sin embargo, no se consideró que la mayoría de sistemas de abastecimiento de las regiones mediterráneas empezaban a registrar un ajuste estructural en los factores de demanda, con reducción del consumo de agua potable, que hubiera obligado a revisar, e incluso a descartar, los proyectos de ejecución de algunas macro-desalinizadoras. Ese reajuste estructural como han comprobado determinados autores para el caso del litoral de la costa de Alicante (Gil et al., 2015; Morote, 2016; Morote et al., 2016) hacen referencia a la reducción del gasto de agua motivado tanto por factores estructurales como coyunturales. Entre los primeros cabe citar: a) una mayor concienciación ciudadana en torno al ahorro de agua; b) uso de tecnologías más eficientes en uso del agua como las aplicadas en grifería, inodoros, duchas y electrodomésticos; c) uso de recursos hídricos alternativos (aguas regeneradas depuradas y pluviales); d) incremento del precio del agua; y e) las mejoras y medidas adoptadas por las empresas suministradoras de agua que han reducido los volúmenes suministrados gracias a la reducción de pérdidas. Mientras que para el caso de los factores coyunturales, cabe mencionar los últimos episodios de sequía (la de 2004/05-2008/09 y la actual desde 2015), cambios sociales y demográficos (pérdida de población), los efectos de la crisis financiera de 2008 y los procesos de reestructuración de las economías urbanas que han incido sobre el consumo doméstico, industrial y comercial de agua.

Analizadas las luces y sombras que ofrece la dependencia hídrica, tanto de transferencias de otras cuencas como de la desalinización, existe la posibilidad de otras alternativas totalmente complementarias. Por ejemplo, sería importante potenciar los intercambios de agua entre entidades de regantes del Tajo y del Segura (art. 67 a 72 del TRLA) y mejorar la calidad de la depuración y la reutilización de aguas depuradas, tanto de la cuenca cedente como receptora para potenciar este recurso no convencional y sustituir determinados usos de agua potable. Para el caso de la primera opción, estas soluciones coyunturales ya han demostrado que pueden ser una opción viable. Por ejemplo, cabe destacar algunas cesiones de agua como la sustitución de riego con aguas del 
Alberche por parte de los regantes del Canal del Bajo Alberche por aguas bombeadas del Tajo a cargo del Canal de Isabel II, con el fin de garantizar el suministro de Madrid con aguas del Alberche durante la sequía de 1993/94 y en 2005 (Estevan \& La Calle, 2007) o para el caso de la MCT que, también suscribió varios acuerdos de cesión temporal de derechos el agua con entidades de regantes del Alto Tajo (Aranjuez) y de la propia cuenca del Segura (Hellín) que posibilitó garantizar los abastecimientos de agua potable a 2,5 millones de habitantes de Albacete, Murcia y Alicante (Gil \& Rico, 2008).

En la cuenca del Segura, cabe remarcar que el uso de las aguas regeneradas depuradas es una realidad desde hace décadas. En la Región de Murcia y en las comarcas del sur de la provincia de Alicante (abastecidas por el ATS, como La Vega Baja o el Bajo Vinalopó), el porcentaje de reutilización es de casi el 100\%. Sin embargo, esto mismo no ocurre con la cuenca del Tajo. Por ejemplo, en la Comunidad de Madrid se reutiliza el 1,98\% (de un total depurado de $573 \mathrm{hm}^{3}$ ), en Castilla-La Mancha el 0,67\% (de un total de $221 \mathrm{hm}^{3}$ ) y en Extremadura el $0 \%$ (de un total de $164 \mathrm{hm}^{3}$ ) (Rico et al., 2016). Sin embargo, cabe destacar algunas de las medidas aplicadas en la última década en la cuenca cedente como la construcción de la Estación de Tratamiento de Agua Potable (ETAP) del Tajo (2007), con un presupuesto de adjudicación de 32,4 millones de euros y subvencionada con 16,2 millones de euros procedentes de los Fondos Feder de la Unión Europea. Dicha planta, localizada en el municipio de Colmenar de Oreja, junto con la construcción de más de 28,9 kilómetros de conducciones conformarán un nuevo subsistema de abastecimiento para la zona sur de la región de Madrid del que se beneficiarán más de medio millón de habitantes, si bien, por problemas de exceso de sales (sulfatos), se precisa desalinizar el caudal derivado. Ello refleja un amplio margen de mejora y uso racional de un recurso que se está desaprovechando y que podría reducir la presión de la demanda de agua potable, con recursos procedentes del río Tajo, por ejemplo. Además, una cuestión que cabe matizar es que se deberían mejorar los sistemas de depuración, incorporando ultrafiltración y desalinización si fuera preciso, para pasar de un sistema secundario a uno terciario que mejoraría la calidad de estas aguas y potenciaría su atractivo como recurso aprovechable sin dejar de atender los caudales ecológicos. También cabe la posibilidad de atender el nuevo incremento de la demanda urbana previsto en la cuenca del Tajo (principalmente para la Región Metropolitana de Madrid) con recursos procedentes desde la cuenca del Alberche donde existen $591 \mathrm{hm}^{3}$ /año de recursos hídricos disponibles y una demanda de $350 \mathrm{hm}^{3} /$ año, y desde la cuenca del Tiétar, con una demanda de $135 \mathrm{hm}^{3} /$ año y unos recursos disponibles de $1673 \mathrm{hm}^{3}$ (Figura 5). 
Figura 5. Situación actual de demandas y recursos en las cuencas

del Tajo y Segura y propuestas de corrección

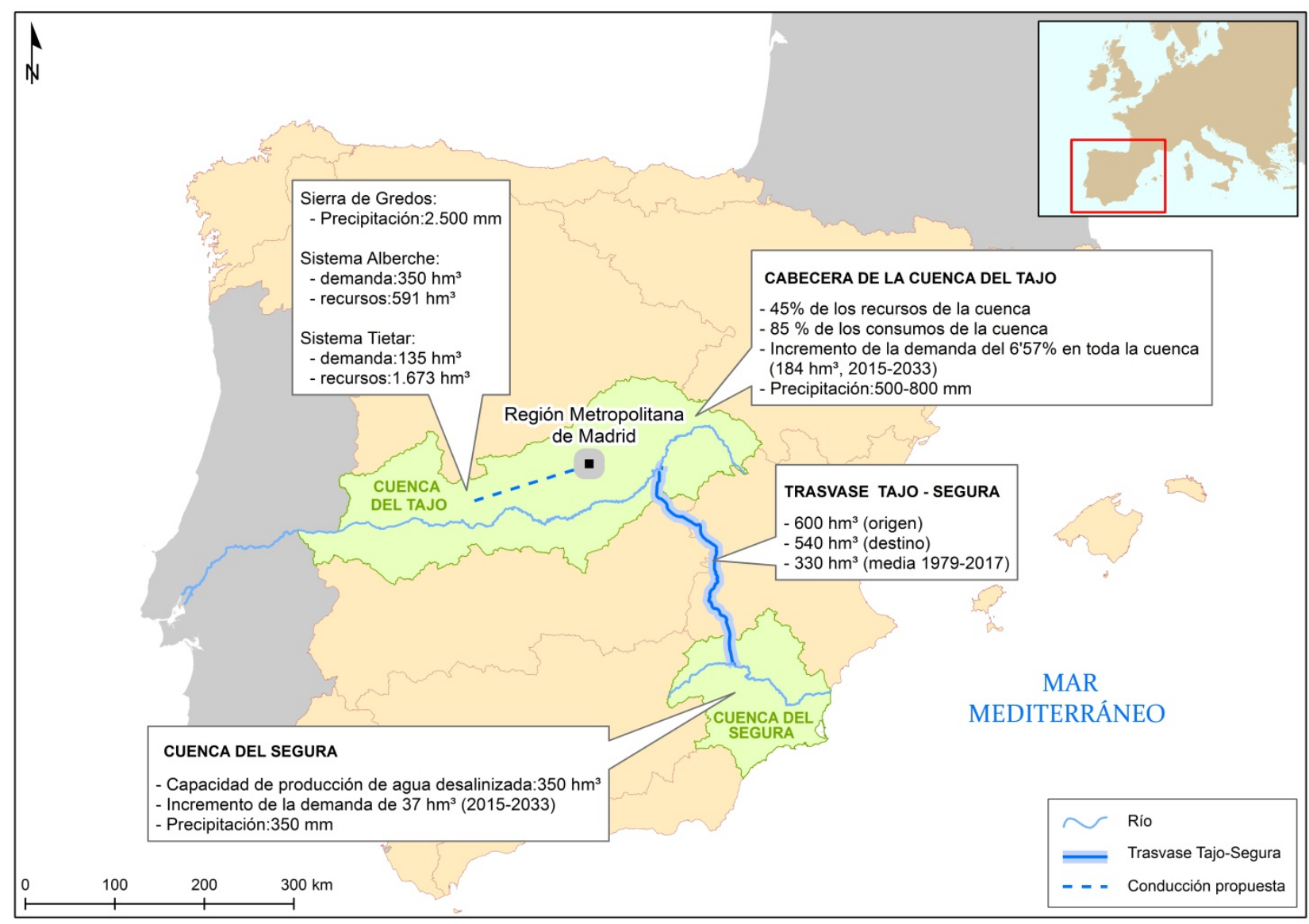

Fuente: elaboración propia

En cuanto a las medidas y soluciones desde la gestión de la demanda cabe destacar que se debería hacer un mejor uso y gestión del recurso agua, tanto por parte de usuarios como de entidades encargadas del suministro y de abastecimiento de agua. Serian medidas a implementar tanto para reducir las pérdidas de la red, incrementar la eficiencia de los sistemas de regadío actuales y evitar la nueva creación de regadíos tanto en la cuenca cedente como receptora. En relación con este último aspecto cabe poner de manifiesto que la superficie de regadío desde principios del siglo XXI se ha incrementado en ambas en cuencas. Por ejemplo, en la cuenca receptora, en la Región de Murcia entre 2002 y 2017 han pasado de 165098 a 183129 ha (un incremento del 10,9\%), mientras que en la cuenca cedente, por ejemplo, en Castilla-La Mancha, esta superficie se ha incrementado en un 20,9\% al pasar de 447333 a 541193 ha (ESYRCE, 2017).

En relación con las demandas, sin embargo, según los actuales planes hidrológicos de cuenca (2015-2021), en la cuenca del Tajo la demanda se ha estimado que aumentará para el horizonte 2033 en un 6,57 \% (184 $\mathrm{hm}^{3}$ ) (de 2800 a $2989 \mathrm{hm}^{3}$ ), principalmente con el aumento de la demanda urbana al pasar de 741 a $931 \mathrm{hm}^{3}$ (incremento del $25 \%$ ) y las industriales de 42 a 
$60 \mathrm{hm}^{3}$ (incremento el $42 \%$ ). Sin embargo, en relación con la demanda agraria se ha estimado una leve reducción del 1,2\% al pasar de 1929 a $1904 \mathrm{hm}^{3}$. Por otro lado, en la cuenca del Segura se ha estimado para ese mismo periodo de tiempo un incremento de la demanda del 2,14\% al pasar de 1726 a $1763 \mathrm{hm}^{3}$. Para el caso de la demanda agraria, ésta prácticamente se mantendrá estable $(+0,20 \%)$, mientras que las que más se incrementarán serán las urbanas con un $11,11 \%$ (de 189 a $210 \mathrm{hm}^{3}$ ).

Otra cuestión que cabría plantearse es si las ayudas recibidas por la PAC son racionales y sostenibles con la subvención de cultivos de regadío y que éstos se lleven a cabo durante situaciones de sequía. Por ejemplo, hay acuíferos donde no se aplica ningún criterio de tipo de condicionalidad ambiental para percibir las ayudas de la PAC, ni tampoco durante situaciones de sequía se fomenta la selección de cultivos con una menor dotación hídrica, cultivos de secano, o incluso que se fomente no cultivar durante estos episodios con ayudas de la PAC.

En cuanto a la modernización de regadíos, en la cuenca del Tajo, como se recoge en el Anexo del Programa de Medidas del Plan Hidrológico del Tajo (2015-2021), cabe citar las actuaciones a tener en cuenta en los tributarios de la margen derecha del Tajo procedentes del Sistema Central, caso del Alberche y Tiétar. Para el caso del primero, se ha planteado el aumento de la eficiencia en el uso del agua en regadío (en particular la modernización de la zona regable del Canal Bajo del Alberche) y en abastecimiento. También se establece una revisión de las normas de utilización del agua por los usuarios del sistema, en particular para reducir la presión de las demandas que disponen de fuentes de suministro alternativas, sin perjudicar la garantía de estas demandas, el ajuste de las asignaciones y en su caso, de las concesiones, a las necesidades reales previstas para los diferentes usos y la duplicación de la conducción Almoguera-Algodor u otra actuación equivalente que permita al sistema de abastecimiento a Madrid la utilización efectiva de la reserva de 60 hm³ del sistema Cabecera, prevista en el Plan Hidrológico, y al sistema de abastecimiento de Picadas, Toledo y Las Sagras, y la reserva de $20 \mathrm{hm}^{3}$ del sistema Cabecera también prevista en el Plan Hidrológico. Para el caso del Tiétar se ha programado igualmente el aumento de la eficiencia en el uso del agua en regadío, en particular la modernización de las zonas regables de Rosarito, Margen Izquierda y Margen Derecha y el incremento de la disponibilidad de recursos hídricos en el sistema mediante actuaciones adicionales de regulación de los recursos naturales. En la cuenca del Segura, en cuanto a la eficiencia de los sistemas de regadío cabe indicar la notable mejora en esta materia. En este sentido, actualmente en el $90 \%$ de las hectáreas que pueden regarse con aguas del ATS está implantado el sistema de riego por goteo donde se alcanza una eficiencia del $85 \%$ en comparación con $65-70 \%$ del sistema de riego a surcos por gravedad o inundación (Plan Hidrológico de la cuenca del Segura, 2015-2021). 
Existe también la opción de llevar a cabo un cierre programado de la actual infraestructura de ATS, pero, esta medida debería contar con el acuerdo de las dos cuencas (cedente y receptora) y debería suponer una serie de medidas de compensación hídrica para los usuarios de la cuenca del Segura que verían sustituidos los caudales de trasvase por otros de procedencia diversa (depuración y desalinización) que, en todo caso, no podría suponer un incremento del precio del agua actualmente soportado. Si se produjera el cierre definitivo del ATS y no se pudiera garantizar el regadío con fuentes no convencionales, los regantes deberían ser indemnizados por las inversiones realizadas durante todos estos años de funcionamiento del trasvase. Su situación patrimonial requeriría una adecuada compensación económica que Melgarejo et al. (2009) han estimado que podría oscilar entre 3021 y 9161 millones de euros. En suma, este último escenario plantea muchas incertidumbres, al margen de los conflictos no menores que generaría en el área receptora y de la repercusión económica inicialmente negativa que tendría, si no se planifica con detalle esta opción minimizando al máximo los costes económicos y la pérdida de empleo en el área receptora. También cabría repensar si el modelo socio-económico implantado en el sureste español es racional y sostenible de acuerdo en la región semiárida en la que se encuentra. Por ello, si no se garantizara el abastecimiento en esta área y se cambiara dicho modelo económico (debido al cierre del ATS e imposibilidad de garantizar el suministro con agua desalinizada), hay autores que ya han propuesto distintas soluciones y alternativas, medidas tanto de indemnización por las inversiones en infraestructuras realizadas hasta el momento, y apoyo a un radical cambio del modelo socio-económico más sostenible y racional con los recursos hídricos en esta región semiárida ante la imposibilidad de atender las demandas actuales (Morote et al., 2017c).

\section{Conclusiones}

En las áreas urbanas y turísticas, la necesidad de planificar los usos actuales y futuros teniendo en cuenta una posible disminución de recursos de agua ha sido puesta de manifiesto por diversos autores en relación con el turismo y los usos del agua (Gössling et al., 2012; Olcina \& Vera, 2016). En este sentido, las acciones de complementariedad en los usos hídricos que incorporan recursos de procedencia diversa se presentan como solución alternativa en territorios con estrés hídrico y con desarrollo de actividades económicas de interés (Rico et al., 2014; Morote \& Hernández, 2017). Se pude afirmar que hoy en día la riqueza productiva del sureste español en un 50 \% depende de la aportación de las aguas del Tajo, por lo que estos territorios receptores deben de ser solidarios con los cedentes y no olvidar nunca su dependencia de aquéllos.

El llamado "Memorándum" se ha considerado un ejemplo muy destacable de gobernanza del agua al acompañarse de un pacto político con el cual se ha pretendido impulsar la planificación hidrológica del Tajo y de las demarcaciones del Júcar y Segura, dando con ello seguridad jurídica y estabilidad institucional a los regadíos y abastecimientos que dependen del Trasvase y, respetando, 
en todo caso, la prevalencia de las demandas en la cuenca cedente que tienen lógicamente carácter prioritario (Melgarejo et al., 2014). En ese pacto político han participado el Estado y las Comunidades Autónomas implicadas en el ATS, como modelo de buena gobernanza del agua en la resolución de conflictos hídricos. En este sentido, la reforma de numerosos preceptos que afectan al ATS a través de la Ley de Evaluación Ambiental de 2013, ha permitido reconocer derechos subjetivos a los usuarios del Trasvase, asegurando estabilidad jurídica, hidráulica, económica y social, sin perjudicar con ello los intereses de la cuenca cedente. Así, las nuevas reglas de explotación, contribuirían a objetivar buena parte de las decisiones de desembalse, con lo que es de esperar que la explotación sucesiva del ATS se realice en un entorno de entendimiento, cooperación y beneficio mutuo (Melgarejo, et al., 2014). No obstante, tras las elecciones autonómicas del 24 de mayo de 2015, se ha avivado la llamada "Guerra del Agua" en torno al ATS, y es de nuevo Castilla-La Mancha quien exige la derogación del Memorándum y el cierre del trasvase.

El agua en España es un bien de dominio público estatal que no pertenece a ningún territorio sino al conjunto del Estado, al servicio del interés general. El art. 149.1.22 de la Constitución establece además que en el caso de las cuencas intercomunitarias (las que afectan a más de una comunidad autónoma) la competencia reguladora es exclusiva del Estado Español. Por lo tanto, el ATS es una obra de Estado, pensado para el interés general, como las autovías, red eléctrica o como los otros cuarenta trasvases que funcionan en el resto del país. En relación con los aspectos económicos, los usuarios del trasvase pagan el $100 \%$ de los costes del agua que reciben (principio de recuperación de costes) y han compensado hasta ahora a las comunidades autónomas de la cuenca del Tajo con más de 412 millones de euros para ser empleados prioritariamente para atender necesidades de los pueblos ribereños de los embalses de Entrepeñas y Buendía.

Además, debe subrayarse que durante mayo de 2017 y marzo de 2018, el ATS ha permaneció cerrado, lo que no ha evitado que el volumen almacenado en los embalses de cabecera se redujese en unos $155 \mathrm{hm}^{3}$, alcanzando en la primera semana de febrero de 2018, un volumen de $238 \mathrm{hm}^{3}$. Los requerimientos ambientales (caudales ecológicos), evaporación y la sequía, unidos a la atención de las demandas agrarias y de abastecimiento del sistema de la cabecera del Tajo explican la evolución de dicho volumen almacenado desde el mes de mayo de 2017.

En la actualidad, hay una necesidad de la revisión de la planificación hidrológica de la cuenca del Tajo (reequilibrio de la cabecera hidrográfica y pluviométrica). Además, a la cuenca del Segura (hasta el cierre del ATS en mayo de 2017) llegaba una media de $336 \mathrm{hm}^{3} /$ año, mientras que el

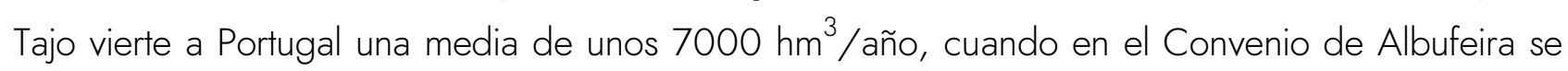
contemplan $2700 \mathrm{hm}^{3}$ y también, cabe advertir que en el peor de los escenarios, las salidas 
fluviales en la frontera con Portugal ascienden a $6300 \mathrm{hm}^{3}$ /año. Por lo tanto, las transferencias de agua a la cuenca del Segura representan tan sólo el 5 \% del caudal que se entrega a Portugal.

En relación con la desalinización, en la cuenca del Segura, cada vez más se está convirtiendo en una fuente ordinaria y sustitutiva de las transferencias del ATS. Gracias a este recurso no cabe olvidar que se están satisfaciendo las demandas para usos urbanos (y en algunos casos la agrarias) evitando de esta manera cortes de suministro y restricciones. Por lo tanto, convirtiéndose este recurso no convencional en un recurso estratégico y de vital importancia durante situaciones de sequía. La situación actual de sequía se ha afrontado con todas las plantas desalinizadoras del Programa A.G.U.A. en funcionamiento, con la excepción de Torrevieja, que tan sólo proporciona $40 \mathrm{hm}^{3} /$ año frente a los $80 \mathrm{hm}^{3} /$ año previstos. Los abastecimientos de agua potable de la MCT tienen garantizado el suministro pero no los regadíos que dependen del ATS, ni los regadíos tradicionales del Segura, que con toda probabilidad volverán a sufrir restricciones de agua. De ahí la necesidad de aplicación de medidas por parte del Estado y las distintas Administraciones con competencias en materia de agua, que también han de incluir necesariamente a las comunidades autónomas por sus competencias en modernización de regadíos, abastecimientos o saneamiento y depuración, pero también a los ayuntamientos que tienen competencia en el servicio de agua potable y saneamiento, o en la elaboración de planes de sequía cuando se superan los 20000 habitantes.

Sin embargo, el propio programa A.G.U.A es una continuación de la política tradicional o "vieja política hidráulica" de aumento de oferta de agua pero, en este caso, a través de la desalinización como alternativa a los trasvases. A pesar de ello, especialmente tras la entrada en vigor de la DMA 2000/60/CE parece que se asiste a una lenta transición de la política de agua, en la que además de velar por la garantía de las demandas de agua, persigue otros objetivos como la participación pública, la recuperación de costes y especialmente el buen estado ecológico de todas las masas de agua. Cabría hacerse entonces la pregunta de si los mega-proyectos hidráulicos (trasvases o desalinización) garantizan el suministro o, sin embargo, posibilitará el aumento de la demanda, convirtiéndose en un recurso que generará más escasez y dependencia. Por lo tanto, cabe indicar que se caería en un error si se pensara que la desalinización (y los trasvases) son las "panaceas" a la escasez de agua en el sureste peninsular.

Tras una dilatada trayectoria en intentar solucionar los problemas de escasez con el incremento de la oferta de agua, cabe indicar que se asiste al reto de intentar paliar dicha escasez desde la gestión de la demanda. Ello consiste, principalmente, en la implicación de todos los usuarios y organismos encargados de la gestión y del suministro de agua con la implementación de medidas conducentes al ahorro y un mejor uso y control del consumo y agua suministrada. Medidas éstas que ya han conllevado a la reducción del gasto de agua desde mediados de la década del 2000 
en el área del sureste peninsular (Morote et al., 2016). No cabe olvidar, para ambas cuencas (Tajo y Segura) la necesidad de adoptar de una mayor eficiencia en el uso y gestión del agua (tanto en usos agrícolas como urbanos), apostando también por el empleo de recursos no convencionales. Además, conviene hacer notar que la cuenca del Segura es una de las áreas donde más se han afianzado los sistemas de riego localizado y la reutilización de agua depurada (tanto directa como indirectamente) para usos agrícolas, ambientales y recreativos (campos de golf). En definitiva, pensar en hacer mejor un buen uso, raciocinio y gestión del agua, y no tanto, en incrementar las demandas.

Dependiendo de la perspectiva con que se analiza, el ATS arroja un balance de luces y sombras no exento de complejidad. En ello intervienen factores políticos, socio-económicos y ambientales, con posturas antagónicas entre las regiones cedentes del Tajo y las receptoras de la cuenca del Segura. Desde su inauguración, en 1979, pero particularmente durante situaciones de sequía, su funcionamiento ha generado en ocasiones situaciones de conflicto auspiciadas por discursos políticos que, lejos de buscar soluciones de consenso, han servido para distanciar las posturas de los defensores y detractores del Trasvase. La solución pasa por lograr un Pacto Nacional del Agua, con amplia participación y consenso de todas las fuerzas políticas. Asimismo, resulta necesaria una mayor coordinación de las políticas sectoriales (Energía, Regadíos y PAC) y de ordenación del territorio (Urbanismo), con la Planificación Hidrológica (Directiva Marco 2000/60/CE, Planes de Cuenca, y Plan Hidrológico Nacional) y sin olvidar la necesidad de resolver los problemas de escasez de agua desde la gestión de la demanda y procurando la mayor eficiencia en el binomio agua-energía. Bajo estas premisas, integradas en un futuro Pacto Nacional del Agua, sería posible configurar un marco político estable y socialmente aceptado de "solidaridad y garantía hídrica" entre todos los actores implicados que evite la "politización" en la gobernanza y gestión de un recurso natural estratégico, en un país donde los mayores desarrollos socio-económicos se encuentran justamente en los territorios con menos recursos hídricos disponibles y expuestos a recurrentes períodos de sequía.

Finalmente, cabría hacerse la pregunta de si es necesario y sostenible el desarrollo de actividades económicas con importantes demandas de agua en áreas con aridez natural (sea el sector agrícola o urbano-turístico) sin tener en cuenta medidas de gestión de la demanda que compatibilicen un menor consumo de recursos hídricos. Y, como estrategia de adaptación a los posibles efectos del cambio climático, debería apostarse por una mayor integración de todos los recursos hídricos disponibles (mix hídrico), teniendo en cuenta tanto aguas de trasvases (cuando estos sean posibles durante periodos de bonanza pluviométrica), desalinización (especialmente durante episodios de sequías), aguas subterráneas, superficiales, uso de aguas regeneradas depuradas y pluviales o los recursos que pueden movilizarse a través de los llamados "mercados del agua". 
Agradecimientos: Esta investigación es resultado del proyecto de investigación "Usos y gestión de recursos hídricos no convencionales en el litoral de las regiones de Valencia y Murcia como estrategia de adaptación a la sequía" (CSO2015-65182-C2-2-P) financiado por el Ministerio de Economía y Competitividad.

Declaración responsable: Las/os autoras/es declaran que no existe ningún conflicto de interés en relación a la publicación de este artículo. Los dos autores han participado en la redacción y análisis de resultados de este trabajo. 


\section{Bibliografía}

Agencia Estatal de Meteorología (AEMET) (2017). Proyecciones Climáticas para el siglo XXI en España. Retrieved from http://www.aemet.es/es/serviciosclimaticos/cambio_climat

Baeza, D. (2013). Estado ecológico de los ríos que forman la red hidrográfica del territorio español de la Demarcación del Tajo. In El Tajo. Historia de un río ignorado (pp. 89-128). Fundación Nueva Cultura del Agua.

Cabello V., Hernandez-Mora N., Serrat-Capdevila A., del Moral L., \& Curley, E. (2017). Implications of spatially neutral groundwater management: Water use and sustainability in the Tucson basin. In Water Bankruptcy in the Land of Plenty (pp. 291-319). CRC Press. https://doi.org/10.1201/b21583CEDEX

CEDEX (2011). Estudio de los impactos del cambio climático en los recursos hídricos y las masas de agua (Informe final). Madrid: Ministerio de Agricultura, Alimentación y Medio Ambiente.

Del Moral, L., \& Silva Pérez, R. (2006). Grandes zonas regables y reparto del agua en España. El caso de la cuenca del Guadalquivir. Mélanges de la Casa de Velázquez, 36(2), 125-148.

Estevan, A., \& La Calle, A. (2007). Transferencias de Derechos de Agua entre Demandas Urbanas y Agrarias: El Caso de la Comunidad de Madrid, Cuadernos de I+D+i 1, Canal de Isabel II. Retrieved from

www.gestioncanal.es/galeria_ficheros/compromisosocial/publicaciones/Cuaderno1_I+D+i.pdf

Estevan, A., La Calle, A., \& Naredo, J. M. (2007). Las series hidrológicas en la instrucción de Planificación Hidrológica. Retrieved from http://www.unizar.es/fnca/docu/docu172.pdf

Encuestas Sobre Superficie y Rendimientos Cultivos (ESYRCE) (2017). Resumen de resultados España y Comunidades Autónomas 2017. Retrieved from

https://preservicio.magrama.gob.es/es/estadistica/temas/estadisticasagrarias/agricultura/esyrce/

Fanlo Loras, A. (2008). El Trasvase Tajo-Segura y su instrumentalización jurídica. Madrid: Cívitas.

Ferreira, M. T. (2013). Calidad ecológica en la Demarcación Hidrográfica del Tajo: Una perspectiva integrada. In El Tajo. Historia de un río ignorado (pp. 145-171). Fundación Nueva Cultura del Agua.

Flores Montoya, F. J. (2004). La Confederación Hidrográfica del Tajo y el Trasvase Tajo-Segura. In Cincuenta Años de la Confederación Hidrográfica del Tajo (pp. 186-212). Madrid: GRAMOSA.

Fragkou, M. C., \& Mcevoy, J. (2016). Trust matters: Why augmenting water supplies via desalination may not overcome perceptual water scarcity. Desalination, 397, 18. http://dx.doi.org/10.1016/i.desal.2016.06.007 
Gallego Bernad, M. S. (2013). El abastecimiento de Madrid y el trasvase Tajo-Segura en la planificación y gestión de la Demarcación Hidrográfica del Tajo. In El Tajo. Historia de un río ignorado (pp. 35-88). Fundación Nueva Cultura del Agua.

Gil Meseguer, E., \& Gómez Espín, J. M. (2017). El trasvase de agua del embalse de Negratín (Granda) al embalse de Cuevas de Almanzora (Almería). La Conexión Negratín-Almanzora (C.NA). Murcia: Universidad de Murcia.

Gil Olcina, A. (2016). Acondicionamiento, rectificación y regulación del Segura. Modificación de lechos, cuenca y régimen fluvial. Alicante: Servicio de publicaciones de la Universidad de Alicante.

Gil Olcina, A., \& Rico Amorós, A.M. (2008). Políticas del Agua II. Mejora y Ampliación de los Riegos de Levante. Murcia: ESAMUR y EPSAR.

Gil Olcina, A., Hernández Hernández, M., Morote Seguido, A. F., Rico Amorós, A. M., Saurí Pujol, D., \& March Corbella, H. (2015). Tendencias del consumo de agua potable en la Ciudad de Alicante y Área Metropolitana de Barcelona, 2007-2013. Hidraqua Gestión Integral.

Gómez Espín, J. (Coord.) (2017). El Trasvase Tajo-Segura. Propuestas para su continuidad y futuro. Alemania: Editorial Académica Española.

Gómez, J. Mª, López, J. A., \& Montaner, E. (Coord.) (2011). Modernización de regadíos: Sostenibilidad social y económica. La singularidad de los regadíos del Trasvase Tajo-Segura. Murcia: Fundación SENECA-SCRATS-Editum.

Gössling, S., Peeters, P., Hall, C.M., Ceron, J. P., Dubois, G., Lehmann, L., \& Scott, D. (2012). Tourism and water use: supply, demand and security. An international review. Tourism Management, 33, 1-15.

Hernández-Mora, N. (2017). The case of the Mancomunidad de Canales del Taibilla. A regional apprach to urban water supply in the context of water scarcity in the region of Murcia (Spain) (Report). Retrieved from

https://www.researchgate.net/publication/322735746_The_case_of_the_Mancomunidad_de_Ca nales_del_Taibilla_A_regional_approach_to_urban_water_supply_in_the_context_of_water_scarcity_i n_the_region_of_Murcia_Spain

Hernández Hernández, M., \& Morales Gil, A. (2008). Trascendencia socio-económica del trasvase Tajo-Segura tras 30 años de su funcionamiento en la provincia de Alicante. Investigaciones Geográficas, 46, 31-48.

Hernández Hernández, M., \& Morales Gil, A. (2009). La Hortofruticultura y las aguas del Trasvase Tajo-Segura: repercusiones socio-económicas. In J. Melgarejo Moreno (Dir.), El Trasvase Tajo- 
Segura: repercusiones económicas, sociales y ambientales en la cuenca del Segura (pp. 413462). Alicante: Caja de Ahorros del Mediterráneo.

Hernández-Mora, N., del Moral Ituarte, L., La-Roca, F., La Calle, A., \& Schmidt, G. (2014). Interbasin Water Transfers in Spain: Interregional Conflicts and Governance Responses. In G. Schneier-Madanes (Ed.), Globalized Water. A Question of Governance (pp. 175-194). SpringerEditors. http://dx.doi.org/10.1007/978-94-007-7323-3_13

Horvath, A., \& Stokes, J. (2011). Life-cycle Energy Assesment of Alternative Suply Systems. International Journal of LCA, 11(335). http://dx.doi.org/10.1065/lca2005.06.214

Intergovernmental Panel on Climate Change (IPCC) (2014). Climate Change 2013 and Climate Change 2014. Retrieved from http://www.ipcc.ch/

Juarez Sanchez-Rubio, C. (1991). Planificación hidrológica y desarrollo económico: El Trasvase Tajo-Segura. Alicante: Instituto de Cultura Juan Gil-Albert.

Mancomunidad de los Canales del Taibilla (2017). Memoria de 2017. Retrieved from https://www. mct.es/web/mct/memorias

March, H., Saurí, D., \& Rico, A. M. (2014). The end of scarcity? Water desalination as the new cornucopia for Mediterranean Spain. Journal of Hydrology, 519, 2642-2652.

March, H., Hernández, M., \& Saurí, D. (2015). Percepción de recursos convencionales y no convencionales en áreas sujetas a estrés hídrico: el caso de Alicante. Revista de Geografía Norte Grande, 60, 153-172.

Martín Barajas, S., \& González Briz, E. (2015). Los efectos del cambio climático sobre el agua en España y la planificación hidrológica. Madrid: Ecologistas en Acción. Retrieved from https://www.ecologistasenaccion.org/IMG/pdf/informe-agua-cc-castellano.pdf

Martínez Fernández, J., \& Esteve Selma, M.A. (2000). Sequía estructural y algunas externalidades ambientales en los regadíos de la cuenca del Segura. Ingeniería del Agua, 7(2), 165-172.

Mccully, P. (1996). Silenced rivers: The ecology and politics of large dams. London: Zed Press.

Mehta, L. (2011). The social construction of scarcity: The case of water in Western India. In R. Peet, P. Robbins, \& M. J. Watts (Eds), Global political ecology (pp. 371-386). London: Routledge.

Melgarejo Moreno, J. (2000). Balance económico del trasvase Tajo-Segura. Investigaciones Geográficas, 24, 69-95.

Melgarejo, J., Molina, A., \& Del Villar A. (2009). La responsabilidad patrimonial del Estado ante la hipotética reducción o cancelación del Trasvase Tajo-Segura. Alicante: COEPA. 
Melgarejo Moreno, J., Molina Giménez, A., \& Del Villar García, A. (2010). El valor socioeconómico del Trasvase Tajo-Segura. Propiedad intelectual de COEPA y de la Fundación de la Comunidad Valenciana de Agua y Progreso. Alicante: COEPA D.L.

Melgarejo Moreno, J., Molina Giménez, A., \& López Ortiz, M. I. (2014). El Memorándum sobre el trasvase Tajo-Segura. Modelo de resolución de conflictos hídricos. Revista Aranzadi de Derecho Ambiental, 29, 1-16.

Morales Gil, A., Rico Amorós, A. M., \& Hernández, M. (2005). El trasvase Tajo-Segura. Observatorio Medioambiental, 8, 73-110.

Morote Seguido, A. F. (2016). La disminución del consumo de agua urbano-turística en la costa de Alicante (España): Una amalgama de causas múltiples e interrelacionadas. Revista de Estudios Regionales, 106, 133-164.

Morote, A. F., \& Hernández, M. (2016). Urban sprawl and its effects on water demand: A case study of Alicante, Spain. Land Use Policy, 50, 352362. http://dx.doi.org/10.1016/j.landusepol.2015.06.032

Morote Seguido, A. F., \& Hernández Hernández, M. (2017). El uso de aguas pluviales en la ciudad de Alicante. De Viejas ideas a nuevos enfoques. Papeles de Geografía 63, 725. http://dx.doi.org/10.6018/geografia/2017/267531

Morote, A.F., Hernández, M., \& Rico, A. M. (2016). Causes of Domestic Water Consumption Trends in the City of Alicante: Exploring the Links between the Housing Bubble, the Types of Housing and the Socio-Economic Factors. Water, 8(374), 118. http://dx.doi.org/10.3390/w8090374

Morote, A. F., Rico, A. M., \& Moltó, E. (2017a). Critical review of desalination in Spain: A resource for the future? Geographical Research, 55(4), 1-12. http://dx.doi.org/10.1111/1745$\underline{5871.12232}$

Morote Seguido, A. F., Rico Amorós, A. M., \& Moltó Mantero, E. (2017b). La producción de agua desalinizada en las regiones de Murcia y Valencia: Balance de un recurso alternativo con luces y sombras. Documents d'Anàlisi Geogràfica, 63(2), 473502. http://dx.doi.org/10.5565/rev/dag.353

Morote, A. F., Olcina, J., \& Rico, A. M. (2017c). Challenges and Proposals for Socio-Ecological Sustainability of the Tagus-Segura Aqueduct (Spain) under Climate Change. Sustainability, 9(11), 1-24. hittp://dx.doi.org/10.3390/su9112058

Olcina, J. (2016, March 31). 37 años. Trasvase Tajo-Segura. Agua que nos une. Especial ABC. Retrieved from http://www.scrats.es/ftp/memorias/ESPECIAL\%20TTS\%20ABC.pdf 
Olcina, J., \& Vera, J. F. (2016). Adaptación del sector turístico al cambio climático en España. La importancia de las acciones a escala local y en empresas turísticas. Anales de Geografía, 36(2), 321-352.

Confederación Hidrográfica del Tajo (2017). Plan Especial de Sequía de la cuenca del Tajo. Retrieved from http://www.chtajo.es/LaCuenca/Planes/Paginas/PlanEspecialSequías.aspx

Rico Amorós, A. M. (2010). Plan Hidrológico Nacional y Programa A.G.U.A.: Repercusión en las regiones de Murcia y Valencia. Investigaciones Geográficas, 51, 235-267.

Rico Amorós, A. M. (2016). La Mancomunidad de los Canales del Taibilla: un modelo de aprovechamiento conjunto de fuentes convencionales y desalinización de agua marina. In J. Olcina Cantos, \& A. M. Rico Amorós (Eds.), Libro jubilar en homenaje al profesor Antonio Gil Olcina (pp. 367-394). Universidad de Alicante, Alicante: Ediciones de la Universidad de Alicante.

Rico-Amorós, A. M., Saurí, D., Olcina-Cantos, J., \& Vera-Rebollo, J. F. (2013). Beyond Megaprojects? Water Alternatives for Mass Tourism in Coastal Mediterranean Spain. Water Resources Management, 27(2), 553-565.

Rico Amorós, A. M., Olcina Cantos, J., \& Baños Castiñeira, C. J. (2014). Competencias por el uso del aguan en la provincia de Alicante: experiencias de gestión en la armonización de usos urbanoturísticos y agrícolas. Documents d'Analisi Geogràfica, 60(3), 523-548.

Rico Amorós, A. M., Arahuetes Hidalgo, A., \& Morote Seguido, A. F. (2016). Depuración y reutilización de aguas residuales en las regiones de Murcia y Valencia. In J. F. Vera, J. Olcina Cantos, \& M. Hernández (Eds.), Paisaje, cultura territorial y vivencia de la Geografía. Libro Homenaje al profesor Alfredo Morales Gil (pp. 1169-1202). Alicante: Servicio de Publicaciones de la Universidad de Alicante.

Sala Díez, I. (2009). El debate sobre el Trasvase Tajo-Segura en los medios de comunicación. In J. Melgarejo Moreno (Dir.), El Trasvase Tajo-Segura: repercusiones económicas, sociales y ambientales en la cuenca del Segura (pp. 587-635). Alicante: COEPA.

Saurí Pujol, D., \& Del Moral Ituarte, L. (2001). Recent development in Spanish water policy. Alternatives and conflicts at the end of the hydraulic age. Geoforum, 32(3), 351-362.

Sindicato Central de Regantes del Acueducto Tajo-Segura, SCRATS (2016, March 31). 37 Años Trasvase Tajo-Segura: Agua que nos une. Especial ABC. Retrieved from http://www.scrats.es/ftp/memorias/ESPECIAL\%20TTS\%20ABC.pdf

Sindicato Central de Regantes del Acueducto Tajo-Segura, SCRATS (2017). Análisis de soluciones para el aporte de recursos complementarios a las zonas abastecidas por el ATS. Actuaciones viables a corto, medio y largo plazo (Report) (Unpublished). 
Swyngedouw, E., \& Williams, J. (2016). From Spain's hydro-deadlock to the desalination fix. Water International, 41(1), 54-73.

Tortajada, C. (2016). Policy dimensions of development and financing of water infraestructura: The cases of China and India. Enviromental Science \& Policy, 64, 177-187.

Valdes-Abellán, J., Pardo, M. A., \& Tenza-Abril, A.J. (2017). Observed precipitation trend changes in the western Mediterranean region. International Journal of Climatology, 37(S1), 1285 1296. http://dx.doi.org/10.1002/joc.4984

Vargas, J., \& Paneque, P. (2017). "Metodología para el análisis de las causas de la vulnerabilidad al riesgo de sequía a escala de Demarcación Hidrográfica. Natural Hazards, 89(2), 609621. htrp://dx.doi.org/10.1007/s11069-017-2982-4

Vera, J. F., Olcina, J., \& Díez, D. (2009). Repercusiones del Trasvase Tajo-Segura en el sector turístico de la Región de Murcia. In Melgarejo Moreno, J. (Dir.), El Trasvase Tajo-Segura: repercusiones económicas, sociales y ambientales en la cuenca del Segura (pp. 465-516). Alicante: COEPA.

World Commission on Dams (2000). Dams and development. A new framework for decision making. London: Earthscan. 